Article

\title{
Integrating Business, Social, and Environmental Goals in Open Innovation through Partner Selection
}

\author{
Ricardo S. Santos $1,2, * \mathbb{C}$, Jose Soares ${ }^{3}$, Pedro Carmona Marques ${ }^{1,4} \mathbb{(}$, Helena V. G. Navas ${ }^{5} \mathbb{D}$ \\ and José Moleiro Martins ${ }^{6,7}$ (iD \\ 1 Instituto Superior de Engenharia de Lisboa (ISEL), Instituto Politécnico de Lisboa, 1959-007 Lisbon, Portugal; \\ carmona.marques@isel.pt \\ 2 GOVCOPP, Department of Economics, Management, Industrial Engineering and Tourism, \\ Universidade de Aveiro, 3810-193 Aveiro, Portugal \\ 3 ADVANCE, Lisbon School of Economics and Management (ISEG), University of Lisbon, \\ 1200-781 Lisbon, Portugal; josesoares@iseg.ulisboa.pt \\ 4 EIGeS, Engineering Faculty, Universidade Lusófona, 1749-024 Lisbon, Portugal \\ 5 UNIDEMI, Department of Mechanical and Industrial Engineering, NOVA School of Science and Technology, \\ FCT NOVA, NOVA University of Lisbon, 2829-516 Caparica, Portugal; hvgn@fct.unl.pt \\ 6 ISCAL, Polytechnic Institute of Lisbon, 1069-035 Lisboa, Portugal; zdmmartins@gmail.com \\ 7 Business Research Unit (BRU-IUL), University Institute of Lisbon (ISCTE-IUL), 1649-026 Lisbon, Portugal \\ * Correspondence: ricardosimoessantos84@ua.pt
}

Citation: Santos, R.S.; Soares, J.; Marques, P.C.; Navas, H.V.G.;

Martins, J.M. Integrating Business, Social, and Environmental Goals in Open Innovation through Partner Selection. Sustainability 2021, 13, 12870. https://doi.org/10.3390/ su132212870

Academic Editor: Ioannis E. Nikolaou

Received: 1 October 2021

Accepted: 15 November 2021

Published: 21 November 2021

Publisher's Note: MDPI stays neutral with regard to jurisdictional claims in published maps and institutional affiliations.

Copyright: (C) 2021 by the authors. Licensee MDPI, Basel, Switzerland. This article is an open access article distributed under the terms and conditions of the Creative Commons Attribution (CC BY) license (https:/ / creativecommons.org/licenses/by/ $4.0 /)$.

\begin{abstract}
Although collaborative networks $(\mathrm{CN})$ are widespread in academia and have come to be even more used in corporations all over the world, they still face several challenges on behalf of the new product development (NPD) context, especially in regard to the selection of the CN's right partner. This becomes even more evident when it comes to promoting sustainable development goals within a CN's activities, by selecting the right partners with a wide consensus from a $\mathrm{CN}^{\prime}$ 's management board, avoiding, therefore, the subjectivity around managers' perception of a CN's partner selection. Therefore, this work attempts to answer this problem, by presenting a softcomputing-based framework, to support the managers' board on partner search and selection. The method presented here is further assessed by using a case study, based on the development of a green product, where, according to the obtained results, it is demonstrated that the proposed approach is extremely effective for partner selection, by assessing and prioritizing each candidate involved. The most suitable candidate that fulfills the $\mathrm{CN}^{\prime}$ s requirements is then selected to be integrated as a future partner.
\end{abstract}

Keywords: sustainability; collaboration networks; new product development (NPD); partner selection; fuzzy logic

\section{Introduction}

Innovation is crucial to improve the core competencies of enterprises and individuals, for the enterprise's progress and even for personal learning [1]. In general, innovation comes from the activities preformed in a group, whether they are social activities or scientific and technological collaboration, which allows them to reach exceptional scientific achievements [2]. Thus, finding suitable partners regarding several knowledge areas is crucial to achieve success with innovation in the collaboration context [3]. In recent years, several human resource management researchers and psychologists have focused on social environment effects as well as social capital's influence on the output from each individual in terms of innovation [4-7].

Some studies have discovered the importance of giving some autonomy to employees, for example, when forming a team from employees with several skills, in order to build positive work environments, which is important to achieve high innovation levels within the firm's employees [5]. 
Additionally, the development of social networks by using social cooperation has provided the SME's collaborators with some sense of collectivity, allowing, therefore, the share of information to develop specific skills or even some expertise $[8,9]$.

Additionally, some studies found in the literature (e.g., [10]) states that innovation, achieved from collaborative networks $(\mathrm{CN})$, can lead toward an efficient allocation of assets, improving at the same time the performance of an organization.

Several studies, focusing on partner selection methods in the collaborative networks context, have been performed to support managers in the coordination of their $\mathrm{CN}$ to increases their innovative performance, with most of them examining their $\mathrm{CN}$ on behalf of different perspectives such as knowledge relevance (e.g., [5]), key CN positions (e.g., [11]), and external available resources, among others.

Other studies have focused on external cooperation as a strategy commonly used for developing new products, since through the contact with external individuals/organizations, new knowledge and competences can be generated [7]. This issue can even help scientific individuals to gain more social capital and, therefore, fill key positions in social networks (SNs) [12].

Some studies also highlight SNs as an important tool to understand the behavior of organizations and to locate the required external assets/resources (e.g., [13]), while others highlight SNs as a mean to reach individual expertise (e.g., [14]).

All these studies highlight the importance of partner selection as a purpose to effectively manage organizational knowledge.

The advances in information systems have allowed professionals to have many available approaches and applications [14], with most of these systems being used by human resource (HR) departments to seek suitable partners to form teams.

However, most of these studies/approaches face some limitations, since most of them are focused on how to find adequate partners, without adequately supporting the $\mathrm{CN}$ manager to manage the $\mathrm{CN}$ effectively, by considering issues such as cost, technical constraints, and time, among other issues.

Additionally, and given the requirements within organizations on behalf of sustainable development (e.g., social and environmental responsibility), there are limited approaches that can support managers to perform a balanced assessment between the criteria, regarding the three known dimensions of sustainability, namely, economic, social, and environmental [15-17].

Furthermore, there is some subjectivity with the assessment of different partners, based on a set of pre-defined criteria, which is associated with the manager's perception. Such subjectivity increases if we have more than one manager/decision agent on CNs to perform such an assessment. In this sense, the inclusion of fuzzy logic methods could minimize the effects of such subjectivity.

Therefore, the absence of works reported in the literature that address all these research gaps into a unique approach to promote sustainable collaborative networks is the main purpose of this work, which proposes a novel method regarding partner selection in the $\mathrm{CN}$ context.

The model's robustness presented here will be assessed by referring to a case study, based on a green project developed in the $\mathrm{CN}$ context, consisting of the development of an electric vehicle. The case study presented here will highlight some benefits of this method (e.g., partner prioritization), as well as some limitations found here, pointing out some future lines of research to overcome them.

Therefore, this paper is organized as follows: Section 2 gives some previous research, regarding the issues treated here, while Section 3 proposes the $\mathrm{CN}^{\prime} \mathrm{s}$ model for assessing and choosing suitable partners from a set of candidates to integrate into the same network. Section 4 presents the case study used here to assess the method's robustness, which is then followed by the discussion of results. Section 5 ends with the conclusions and future research. 


\section{Literature Review}

\subsection{Collaboration Networks and Partner Selection: An Introduction}

Due to an increasingly dynamic the global market, there is a crescent search of suitable resources and competencies to develop more competitive products/services. Therefore, more virtual enterprises (VEs) are arising. A VE is an organization, formed by a group of collaborative organizations, with the purpose of defining a temporary alliance to share resources and competencies, to conceive highly innovative products.

In order to pursue such a goal, a VE is formed through a collaborative network $(\mathrm{CN})$, where several companies are gathered to produce highly innovative services/products to suit the consumers' requisites (Figure 1).
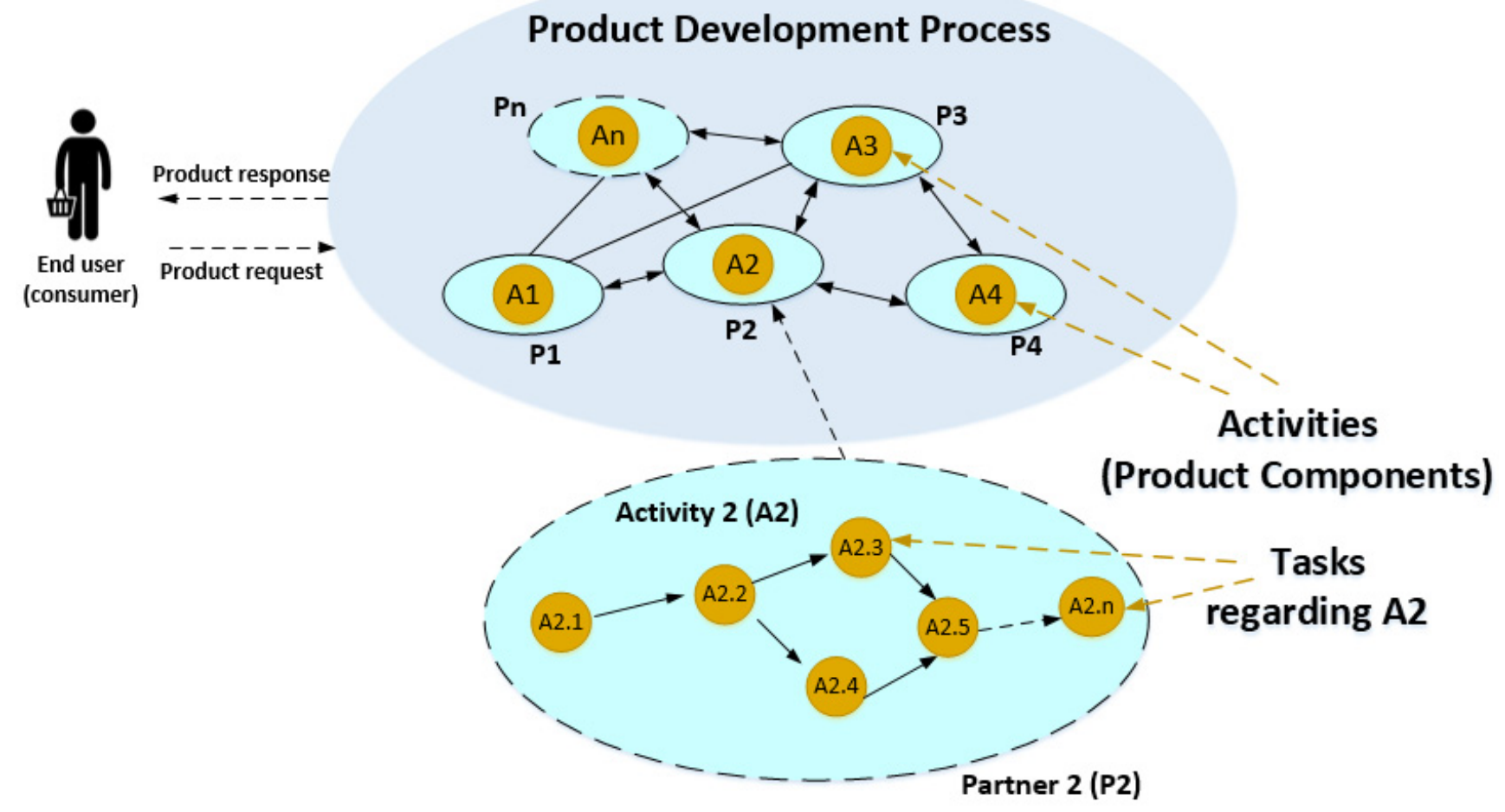

Figure 1. Process (Pn), activities (An), and related tasks (An.n) in a collaborative network (CN).

Other goals, regarding the establishment of a VE, can also include the need of achieving high effectiveness and efficiency levels, by reaching the necessary competencies and resources at a lower cost, when compared to the situation of acquiring those assets separately, when an organization "acts alone" and, therefore, needs to buy them $[8,9]$. Even if it were possible by the traditional way, it would reduce operational efficiency and, therefore, the organization's competitiveness regarding the same product. Additionally, VEs can obtain access to more capital and technologies through collaboration, serving, therefore, the consumers in a fastest way, being more flexible to market opportunities and threats.

Thus, and with regard to the OI's context, new product development (NPD) can be assumed as an integrated process, which is formed by a set of activities, each one related to a specific system/product's component (Figure 1).

Therefore, each activity can be executed by one or more of a CN's partners, which are involved on behalf of the VE created, being hence considered as a product/system component, formed by a set of individual tasks, related to an activity $n$ (An). Thus, each activity can be defined as a separate project that needs to be managed. Through the combination of all processes and activities involved results the final product/service, which is the main purpose of the $\mathrm{CN}$ originally created. 
This product/service can be considered, therefore, an integrated project, which will demand efficient and effective management, given the competencies and resources involved.

Nowadays, and increasingly within the complexity that exists in each $\mathrm{CN}$ project (e.g., increases in the number of partners/processes involved), the selection process of the "right partner" can represent a difficult task to be performed by the CN's managers, given the requirements initially established [18].

In order to achieve a sustainable and competitive advantage, organizations need to provide new or even improved services/products, which includes processes, by using their reliable partners, and suppliers, together with an efficient and effective supply chain. The increasing competition within global markets forces companies to accelerate their product's development to a better quality, in order to meet their customers' needs and expectations in a very short time and to attain economic and competitive advantage [19]. As is mentioned above, and to answer this issue, organizations can enter into collaboration networks (CN), which implies (almost) new demands, given the multidisciplinary integration needed to create highly innovative products [20]. It is defended though the literature that CNs can decrease NPD costs, as well as short-order cycle times, improving, therefore, the quality of the products and reducing the risk with delays in delivery at the same time [20,21]. Although, it must be highlighted that the option for CN can impose new risks to the success of NPD, which includes the production capacity [21]. Hence, and given what was referred to before, it becomes necessary to undertake the supplier assessment process carefully, to guarantee a suitable selection.

Additionally, and given the increasing requirements within organizations on behalf of sustainable development, which includes social and environmental responsibilities, there are few approaches in the literature to support managers in partner selection regarding CNs and on behalf of the three sustainability dimensions, i.e., social, environmental, and economic [12].

Some studies have essentially focused on the selection of the supplier, suitable for the CN (e.g., [22,23]). Normally, in these studies, a set of steps is made, where the first one starts with the problem definition, by identifying possible candidates/suppliers, regarding a new product/component, where a set of candidates are then selected, to be further assessed according to a set of criteria. Then, the best candidate is chosen, by applying analytical techniques, regarding multicriteria decision-making (MCDM) methods, in order to select and evaluate a set of potential candidates to be further ranked according to the decision maker's (DM) preferences [24].

\subsection{Partner Selection by Using Multicriteria Decision-Making (MCDM) Approaches}

The use of MCDM methods allows for the resolution of complex and highly uncertain problems, which have different and conflicting interests and objectives [25]. In recent years, several works regarding MCDM methods have been presented and debated. The usability of such methods were then proved thanks to their highly effectiveness and efficiency on decision making, by selecting and weighting the most suitable solutions/scenarios/alternatives according to the DM's preferences [26]. However, MCDM often needs the DMs to assess and express their judgments (based on their perception) to measure the alternatives, according to a set of criteria, in order to map out the problem to be solved [27].

Therefore, and considering partner selection as an MCDM problem, such process, although usually uncertain, given the subjectivity with the DM itself, is strategic, which implies some risks and vague parameters. The situation can be more complex when we consider that there is a need to perform such decisions in groups, which is the case in partner selection on behalf of OI projects.

Nevertheless, some researchers (e.g., [28]) have pointed out the need for developing MCDM methods to face the problems involving group decision making (GDM) on partner selection. In this context, GDM normally involves several experts whose interaction among each other allows the achievement of a consensus between them [27]. 
Each one of the decision makers (DMs) that compose the CN (group) normally have different perceptions and goals according to the organization where he/she comes from.

Thus, everyone can affect the decision process in a different way from the rest of the group. Since for the OI, there is a common interest to reach some consensus on selecting the suitable alternative/partner, there is a need to obtain a method that allows them to achieve some consensus when selecting the most suitable partner for the CN [29].

As is referred to before, several studies analyzing the successful deployment of OI approaches have been conducted, with many of them receiving different designations such as "managing OI" (e.g., [30-32]) or even "OI on practice " [33].

However, many studies can be considered as quite broad from the point of view of partner search and selection, as well as project planning.

Many of them provide an overview or even different frameworks to frame OI as a concept (e.g., [34-38]) or even analyze the effects of OI across the organizations, either on a macro perspective level (considering the $\mathrm{CN}$ as a whole) or on a micro perspective level (considering each partner involved), which includes general "lessons" concerning when and what to do, although without accounting the how to search and select the "right" OI partner [31], despite the existence of some preliminary studies around this theme. For instance, the study of [38] identifies the relevance of locating suitable CN partners, and it also provides generic recommendations on how to locate them. In order to surpass some of these limitations, other studies have included more details, by referring, for instance, to in-depth case studies on a specific type of OI and $\mathrm{CN}$ partner, such as crowdsourcing (e.g., $[39,40]$ ), or even those regarding the innovation related to the crossindustry [41]. Other studies have suggested specific partner types, regarding determined innovation problems (e.g., [42-46]). This study also accounts for these approaches with the aim of increasing generalizability.

However, most of these studies do not consider the importance of including criteria regarding sustainable development through its social and environmental dimensions.

Additionally, even more studies (e.g., [21,26,42]) have demonstrated the importance of these two dimensions, respectively, through environmental and social responsibility on the enterprise's ecosystem and, most of all, their importance for society in general, by considering future generations.

Some studies have also analyzed the relationship regarding the number of $\mathrm{CN}$ partners and the CN's overall performance, resulting from the innovation achieved [43].

This is somehow aligned with other works from the literature, which allows us to conclude that the excess of breadth brings negative impacts over the innovation performance of the CN, whether in terms of novelty or in the efficiency archived $[47,48]$. While this highlights the relevance of a purposeful CN partner, one of the key challenges identified by the literature is related with the bias within the local search, where enterprises tend to achieve some commitment with the already known organizations [49]. A study referred to in [50] presents a conceptual approach to overcome this issue by supporting the decision among four general search paths, namely scientific, situated, analogical, and sophisticated. These general paths are based on a distant and local search space, which is performed by using heuristic methods. On behalf of managing CNs in SMEs, the study from [51] offers some guidelines on $\mathrm{CN}$ partner selection, which includes criteria around the partners' "hard skills" and capabilities, such as resources, competencies, and risk appetite, as well as partners' similar ambitions and personal relationships.

The study from [52] gives some support by offering a "checklist" of selection criteria, related to socio-technical issues, although it is not considered criteria regarding social responsibility, with all known advantages already referred to before and identified in studies such as [21].

Moreover, the inclusion of these concerns on partner selection allows us to better promote the product to be developed within the market in general [26,50].

There are also other studies found in the literature, where, given the diversity of knowledge-based areas involved, they can be categorized into different areas, such as 
network-based studies, resulting from each existing CN's organization network and its relationship with old (and potential) partners, in order to be further identified and preassessed (e.g., [53-56]); database-based studies, by using determined databases, related with existent suppliers and patents, with the search and selection involved here, varying from simply search involving key words up to the use of proximity or distance mapping to locate potential $\mathrm{CN}$ partners (e.g., [57-60]); algorithm-based studies, by using optimization models and algorithms (e.g., [61]) and big data (e.g., [62-64]) to obtain suitable CN partners; open call, which can include a call for participation, regarding the selection of potential CN partners (e.g., [65]), and an innovation contest (e.g., [61]); open search, which can be based on a media cross-industry search (e.g., [63],) or even based on a search engine (e.g., [64]); pool-based, where the potential partners are identified from an existing group (pool) of actors, based on a set of criteria (e.g., [65,66]); delegated, by using OI intermediary agents (e.g., [67-69]).

Despite the diversity of the $\mathrm{CN}^{\prime} \mathrm{s}$ approaches, existent in the literature, they usually focus on a specific OI type and do not perform a holistic approach toward $\mathrm{CN}$ partners, based on sustainable development criteria, which would allow for a better promotion of the developed product within the market in general $[21,26,70,71]$ with all the positive externalities for the society, as discussed before.

Other studies involve the application of fuzzy-logic-based approaches to express linguistic terms in DM processes [29].

The analytical hierarchical process (AHP) method is one of the most popular approaches that can be found in the scientific literature. Its original development comes from the works of Saaty [24], and it represents a renowned decision-making method widely adopted in operations and management sciences research. This method allows for the definition of priorities on behalf of multicriteria decision making (MCDM), by simplifying complex structures, regarding MCDM exercises/problems, into a simpler one, in order to decide on an alternative between a set of different and available solutions [68].

One of AHP's (Analytic Hierarchy Process) advantages is the search of consistency on its judgments, which is achieved by allowing users to formulate their judgments regarding their problems in a hierarchical way, which are then formed by a set of integrated values [26]. Although its use has a good reputation in the literature, AHP is sometimes criticized, since it is ineffective when dealing with the ambiguity associated with human's subjective perceptions [29]. It might even be possible that a decision maker (DM) feels some uncertainty when performing a pair-wise comparison between each alternative [68].

A solution to be considered could be applying the AHP method on the relative importance, given for each criterion (materialized by the weights), and then applying fuzzy logic to deal with the DM's subjectivity, by providing, therefore, a more flexible and robustness method to attend to the DM's needs, when it comes to expressing their preferences [26].

Some approaches have been developed that integrate MCDM methods such as AHP with fuzzy logic (e.g., [68]). Another MCDM method widely used in the literature, which is also integrated with fuzzy logic, is the TOPSIS approach. This method was first developed from the works of [28], and it is based on a systematic and quite simple calculation routine, followed by sound logic, which can include human rationality. Some works that integrate TOPSIS with fuzzy approaches can be cited (e.g., [69]). Several advantages with the use of this method can be identified here, such as the allowance of a wide range of criteria and related attributes to be included, the ability to account for the trade-offs among the identified attributes [28], and the ability to quickly identify the best scenario/alternative [24].

From the literature review, preformed on behalf of this study, it can be observed that the most used approaches that integrate fuzzy logic to solve MCDM problems are the ones that use AHP and TOPSIS methods.

However, and despite such advantages in its popularity, TOPSIS also presents some disadvantages when compared with AHP, especially when dealing with human perception, 
on defining the relative importance around each criterion, since AHP can better express the DM's preferences, through the corresponding weights, rather than TOPSIS.

Regarding applications of some of the MCDM approaches referred to before, it can be included that the integrated TOPSIS approach, proposed by $[69,70]$, is used to evaluate different renewable energy production technologies in Turkey, as well as the approach from [32], used for ranking the scenarios/alternatives in problems of the MCDM type.

From the literature review performed in this study, we have highlighted the existence of some limited studies involving industrial applications, especially when applied on real applications, regarding open innovation (OI) or collaborative networks $(\mathrm{CN})$.

Additionally, there are few studies, regarding partner selection, that deal simultaneously with human perception and OI's criteria, to select suitable partners for a $\mathrm{CN}$.

Most of the few applications existing are mainly related with supplier selection (e.g., $[27,35,61])$, and there seems to be a gap in using an integrated approach that combines AHP with fuzzy logic in the selection of partners in the OI context. In this sense, this study aims to contribute to the state-of-art, by presenting a real application/case study to show how enterprises can perform decisions by dealing with the uncertainty, in regard to selecting the suitable partner for a collaboration network $(\mathrm{CN})$.

\section{Proposed Approach}

\subsection{Adopted Criteria}

Following what was referred to before, a collaborative network $(\mathrm{CN})$ normally arises to conceive specific products/systems, by allocating different resources and competences from a set of partners, in order to reach high levels of innovation at a lower cost. However, the partner selection for the same $\mathrm{CN}$ arises multiple challenges, especially when it is intended to promote sustainability within the $\mathrm{CN}$ itself on developing such products/systems.

According to [71-74], sustainable development actions can be divided into three main groups or dimensions: economic, social, and environmental (Figure 2).

\section{Inputs}

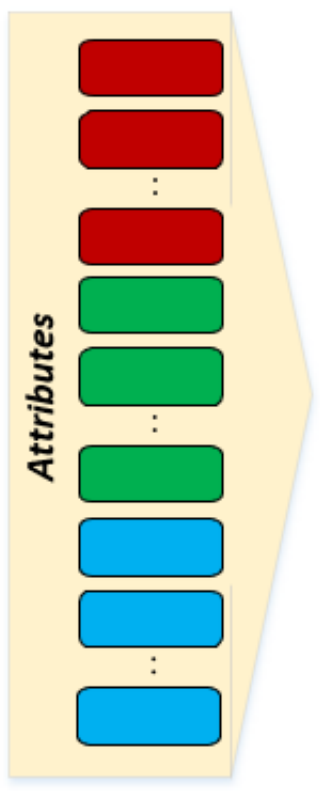

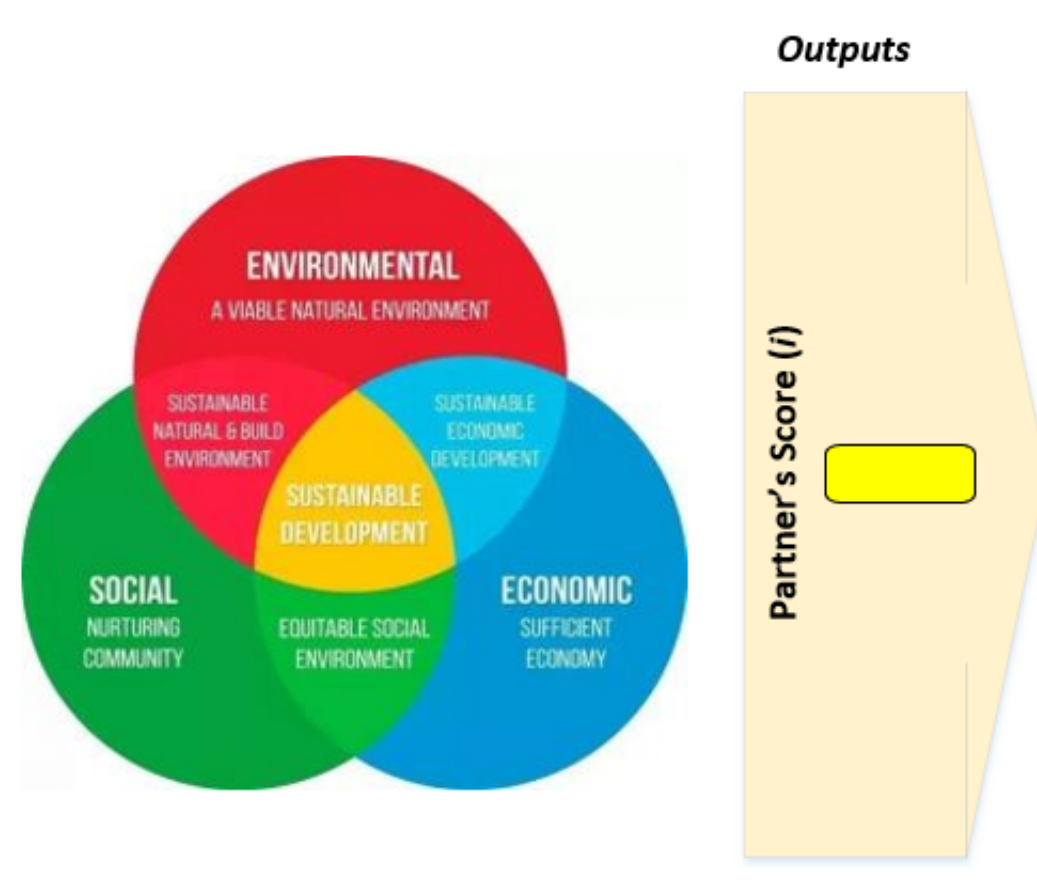

Figure 2. Model's 1st approach.

From the literature, and regarding the criteria normally used in partner selection for $\mathrm{CNs}$, we have found a set of criteria, which we have categorized, according to the three dimensions defined before, i.e.,: 
- Economic: Concerns all the criteria that might impact the $\mathrm{CN}^{\prime}$ 's economic and financial viability, which includes issues mainly related with the organization's economic wellbeing [15], namely, facility location [37,42,56], supply chain channels (distribution points, transportation modes, etc.) [42], scale (available) of operations [56,69], operation costs [75,76], financial situation and credibility [37], capacity of facilities [42], and reliability of feedstock supply [15], among other criteria.

- Social: Concerns all the criteria that might impact the CN's social viability, which can include issues mainly related with the organization's social wellbeing with their stakeholders as well as reputation and share of knowledge/information issues [23], i.e., social responsibility actions (e.g., employees' family members, health insurance, local population, etc.) [42], work conditions [23], availability to share knowledge and information [70], knowledge relevance, reputation, and number of partnerships firmed with other organizations [71], among other criteria.

- Environmental: Concerns all the criteria that might impact the $\mathrm{CN}^{\prime}$ 's environmental viability [15], which includes issues mainly related with the organization's environmental responsibility [75], namely, self-energy greenhouse gas (GHG) emissions [15,40,73], soil and water quality [40], circular economy policies [67], and environment standards accreditation [15,73], among other criteria.

Based on those criteria, a framework to evaluate each partner's potential as a candidate to be integrated into a $\mathrm{CN}$ was created. Thus, in Table 1, an example of the framework is presented, considering a set of criteria, categorized according to the dimensions of sustainability, referred to before.

\subsection{Problem Formulation}

Thus, and based on the criteria presented in Table 1, it can be defined that an attribute $x$, which belongs to an alternative (potential partner) $i$, regarding a sub criteria $j$, which is then related to a dimension/criteria $g$, resulting, therefore, in $\left(x_{i j}^{g_{j}}\right)$. For each criterion, $g$ related each one to a dimension of sustainability, is corresponded a set of sub criteria, which is then applied to assess each potential partner candidate, by using multi-attribute value theory (MAVT).

Therefore, there is a dimension/criteria $g$, regarding to a specific sub criteria $j$, used here $\left(g_{j}\right)$, which can be represented as follows; A-economic, B-social, and Cenvironmental. In general, each attribute $x_{i j}^{g_{j}}$ can be defined, according to:

$$
\begin{gathered}
x_{i j}=\left\{x_{i 1}, x_{i 2}, x_{i 3}, . ., x_{i n_{g}}\right\} \wedge n_{g}=\left\{n_{A}, n_{B}, n_{C}\right\} \wedge n_{A}, n_{B}, n_{C}, i, j \in \mathbb{N} \\
g_{j} \in\left\{\left\{A_{1}, A_{2}, . ., A_{j}, \ldots A_{n_{A}}\right\} \cup\left\{B_{1}, B_{2}, . ., B_{j}, . ., B_{n_{B}}\right\} \cup\left\{C_{1}, C_{2}, . ., C_{j}, . . C_{n_{C}}\right\}\right\}
\end{gathered}
$$

Thus, each attribute $\left(x_{i j}^{g_{j}}\right)$ considered here can be aggregated in just one pay-off table (Table $2(\mathrm{a})$ ). Since each attribute $\left(x_{i j}^{g_{j}}\right)$ works with different scales and units, the correspondent attribute values were then converted by using MVAT, to its correspondent value $\left(v_{i j}^{g_{j}}\left(x_{i j}^{g_{j}}\right)\right)$, by using the "worst" and "better" results obtained through a set of alternatives and related to each criteria $g_{j}$, i.e.,:

$$
x_{i j}^{g_{j}} \rightarrow\left(\frac{\left|x_{i j}^{g_{j}}-x_{i j(\text { worst })}^{g_{j}}\right|}{\left|x_{i j(\text { better })}^{g_{j}}-x_{i j(\text { worst })}^{g_{j}}\right|}\right) \rightarrow v_{i j}^{g_{j}}\left(x_{i j}^{g_{j}}\right)
$$


Table 1. Adopted criteria and pay-off table, used as a 1st approach to define the model.

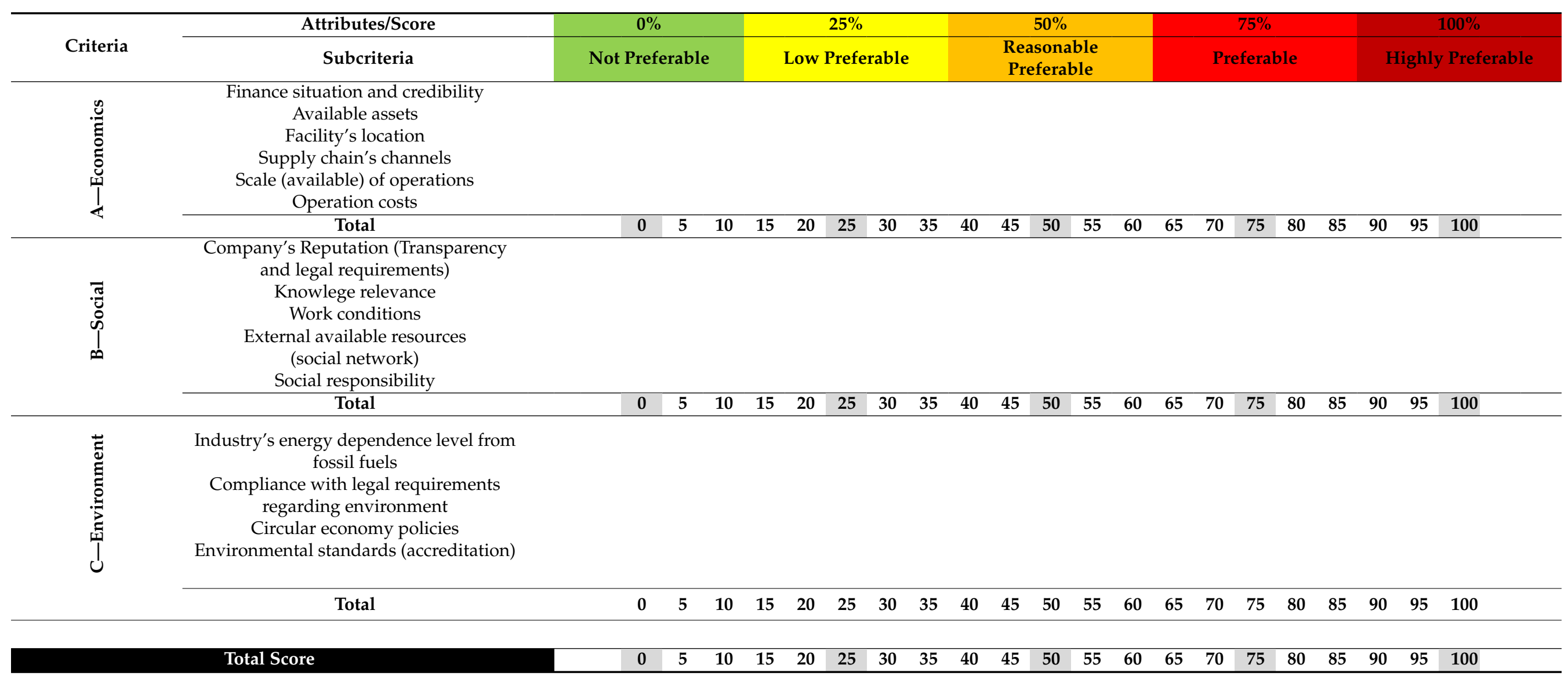


Table 2. Pay-off table, used to define model's criteria: (a) $x_{i j}^{g_{j}}$; (b) $v_{i j}\left(x_{i j}^{g_{j}}\right)$.

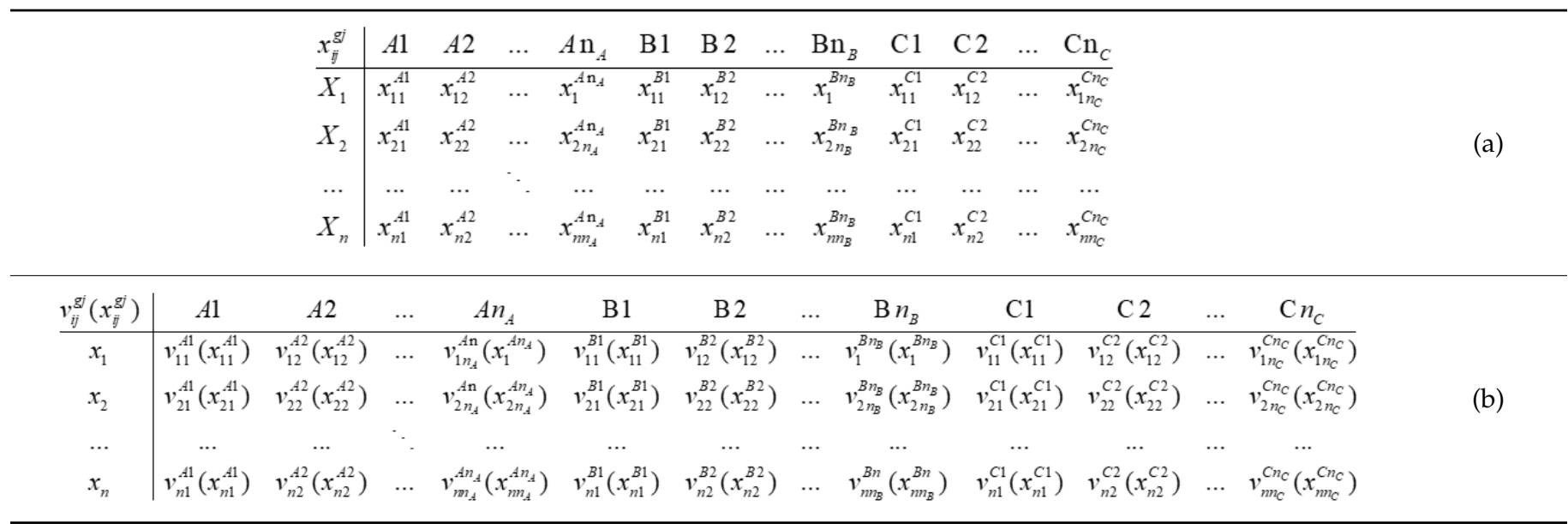

The new values, referred to each $v_{i j}^{g_{j}}\left(x_{i j}^{g_{j}}\right)$, have originated in a new pay-off table, which is the result of the conversion of Table 2 (a), to Table 2 (b), by using (3).

Through the attributes previously defined, and by using fuzzy logic techniques, the correspondent value functions $V_{i}^{A}\left(x_{i}^{A}\right), V_{i}^{B}\left(x_{i}^{B}\right)$, and $V_{i}^{C}\left(x_{i}^{C}\right)$ were achieved, regarding each sustainability dimension. Then, and by using an additive model based on the MAVT approach, a unique expression to aggregate all dimensions was achieved, in order to assess each alternative/potential partner. This function was then weighed by a weight factor $\left(\omega_{g}\right)$, expressing, thus, the relative importance given to each dimension of sustainability, resulting, therefore, in the final assessment function, i.e.,:

$$
V_{i}\left(X_{i}\right)=V_{i}\left(V_{i}^{A}\left(x_{i}^{A}\right), V_{i}^{B}\left(x_{i}^{B}\right), V_{i}^{C}\left(x_{i}^{C}\right)\right)=\omega_{A} \cdot V_{i}^{A}\left(x_{i}^{A}\right)+\omega_{B} \cdot V_{i}^{B}\left(x_{i}^{B}\right)+\omega_{C} \cdot V_{i}^{C}\left(x_{i}^{C}\right)
$$

with $\omega_{A}, \omega_{B}, \omega_{C}$ being achieved by using the analytical hierarchical process (AHP) method, as is presented and described in following sections.

\subsection{Model Architecture}

The proposed model's architecture intends to integrate all the issues, referred to before with fuzzy inference systems, to support managers into the development of a product on behalf of a collaborative network (CN) (Figure 3). Additionally, the integration of fuzzy logic has the purpose to cope with ambiguity and subjectivity, related with human perception on assessing each potential partner, according to a set of criteria previously defined.

The proposed approach is presented in Figure 3.

Based on Figure 3, each alternative/potential partner $i$ has a set of individual scores $v_{i j}^{g j}\left(x_{i j}^{g j}\right)$, which are correspondent, each one, to a given criteria/dimension $(g)$ related to each sub criteria $j$, which is then used as an input regarding each correspondent fuzzy logic (relating each one to a specific dimension/criteria). By using Mamdani as a fuzzy inference mechanism, and through a set of inference rules, regarding a fuzzy heuristic rule of the type "If ... And ... Then", the overall score of each criterion is obtained, regarding each potential partner $i\left(V_{i}^{g}\left(x_{i}^{g}\right)\right)$.

A fuzzy-logic-based system can be applied to decision-making problems, by providing a formal methodology, which allows for the representation, manipulation, and implementation of human heuristic knowledge, regarding how to support the decision agent when it is asked to perform smart decisions (e.g., [9]). Each one of the fuzzy systems presented in Figure 3 can be represented by a block diagram, such as the one shown in Figure 4 . 


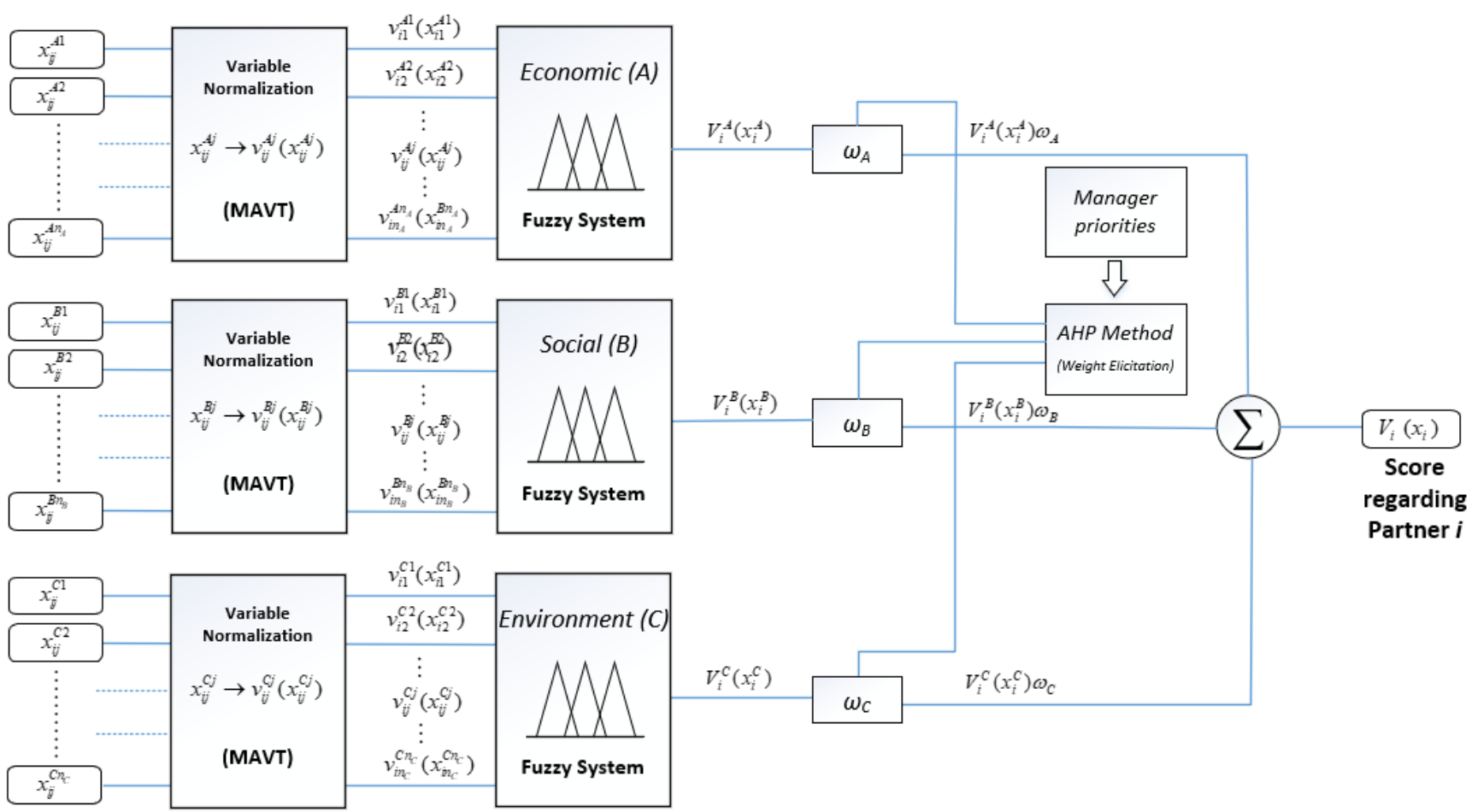

Figure 3. Proposed model.

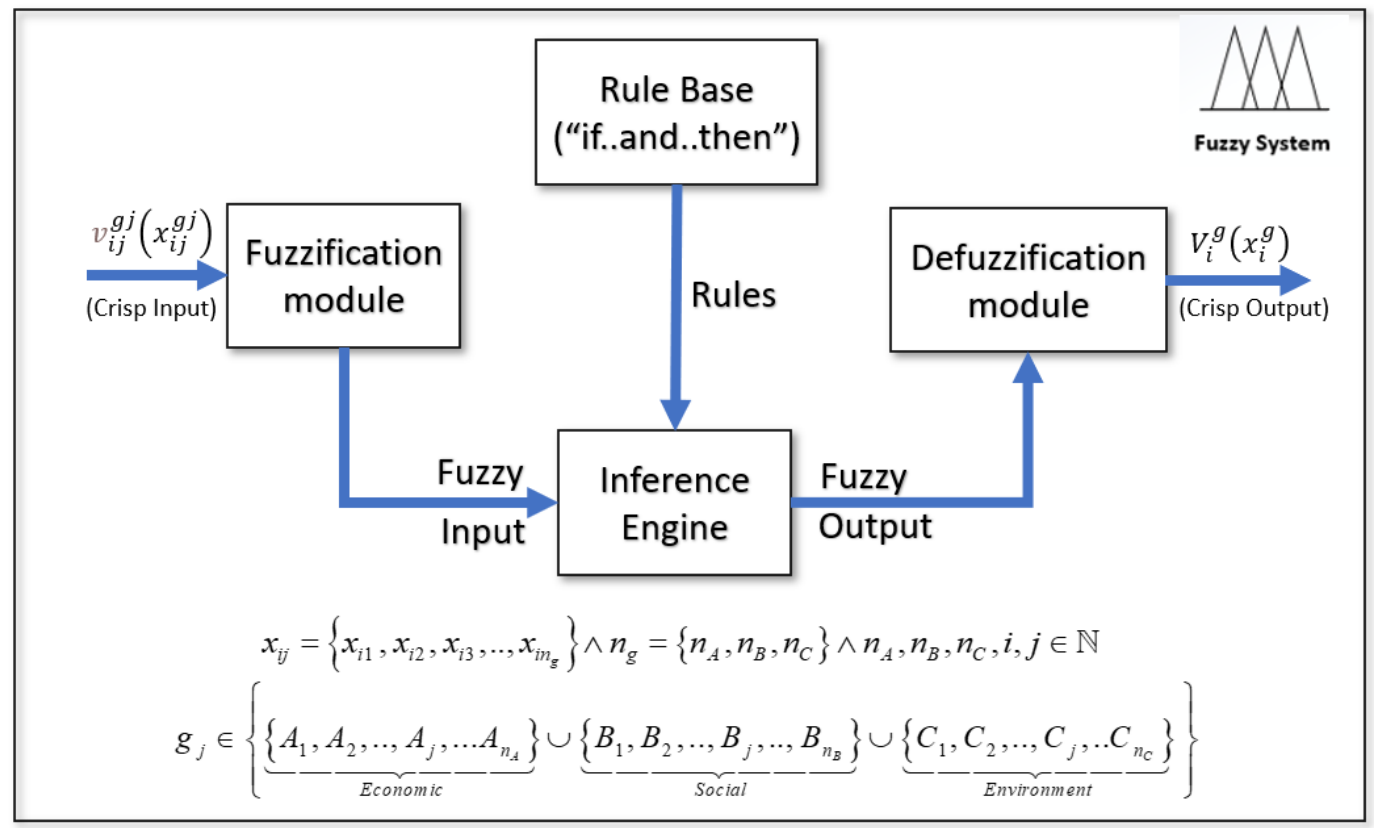

Figure 4. Fuzzy system block diagram.

Thus, based on Figure 4, and in order to preform decisions, this system makes use of four main components, namely:

- Fuzzification-used to modify the inputs to be analyzed and compared with the rules, originated from the rule-base module.

- Inference mechanism - used to assess which decision rules are important at a given instant time, in order to further decide what should be the decision to be performed. 
- "Rule-base" - holds the based knowledge, materialized on a set of rules on how perform the best decisions.

- Defuzzification-converts the main conclusions achieved by the inference engine/ mechanism into a series of decisions regarding partner selection.

The antecedents, associated with the rule type adopted here, are correspondent to each sub-criteria adopted in this methodology, which in this case, are presented in Table 1.

Therefore, and based on Figures 3 and 4 , each $V_{i}^{g}\left(x_{i}^{g}\right)$ is achieved by using a set of correspondent functions, based on the following expressions (5-7) and from the inputs $v_{i j}^{g j}\left(x_{i j}^{g j}\right)$, i.e.,

$$
\begin{aligned}
V_{i}^{A}\left(x_{i}^{A}\right) & =v_{i 1}^{A 1}\left(x_{i 1}^{A 1}\right) \cap v_{i 2}^{A 2}\left(x_{i 2}^{A 2}\right) \cap \ldots \cap v_{i j}^{A j}\left(x_{i j}^{A j}\right) \cap \ldots \cap v_{i n_{A}}^{A n_{A}}\left(x_{i n_{A}}^{A n_{A}}\right) \\
V_{i}^{B}\left(x_{i}^{B}\right) & =v_{i 1}^{B 1}\left(x_{i 1}^{B 1}\right) \cap v_{i 2}^{B 2}\left(x_{i 2}^{B 2}\right) \cap \ldots \cap v_{i j}^{B j}\left(x_{i j}^{B j}\right) \cap \ldots \cap v_{i n_{B}}^{B n_{B}}\left(x_{i n_{B}}^{A n_{B}}\right) \\
V_{i}^{C}\left(x_{i}^{C}\right) & =v_{i 1}^{C 1}\left(x_{i 1}^{C 1}\right) \cap v_{i 2}^{C 2}\left(x_{i 2}^{C 2}\right) \cap \ldots \cap v_{i j}^{C j}\left(x_{i j}^{C j}\right) \cap \ldots \cap v_{i n_{C}}^{C n_{C}}\left(x_{i n_{C}}^{A n_{C}}\right)
\end{aligned}
$$

Thus, and through $V_{i}^{A}\left(x_{i}^{A}\right), V_{i}^{B}\left(x_{i}^{B}\right)$ and $V_{i}^{C}\left(x_{i}^{C}\right)$, an expression to assess each alternative/potential partner $i$ is achieved, i.e.,:

$$
V_{i}\left(x_{i}\right)=V_{i}\left(V_{i}^{A}\left(x_{i}^{A}\right), V_{i}^{B}\left(x_{i}^{B}\right), V_{i}^{C}\left(x_{i}^{C}\right)\right)=\omega_{A} \cdot V_{i}^{A}\left(x_{i}^{A}\right)+\omega_{B} \cdot V_{i}^{B}\left(x_{i}^{B}\right)+\omega_{C} \cdot V_{i}^{C}\left(x_{i}^{C}\right)
$$

with $\omega_{A}, \omega_{B}, \omega_{C}$ satisfying the following condition:

$$
\omega_{A}+\omega_{B}+\omega_{C}=1
$$

These three weights are achieved by using the analytical hierarchical process (AHP) method.

Concerning the linguistic variables and based on $[23,30]$, it is advised that the number of linguistic levels should not surpass nine, given the eventuality of surpassing the decision agent's perception limits, when it is wanted to discriminate such values.

\subsection{Fuzzy Deployment}

Based on the model's architecture presented in Figure 3, each fuzzy system (FS) was implemented by using MATLAB $^{\circledR}$ software (version R2015b) (Figure 5), where a set of membership functions was included (Tables 3 and 4) and inference rules were previously defined.

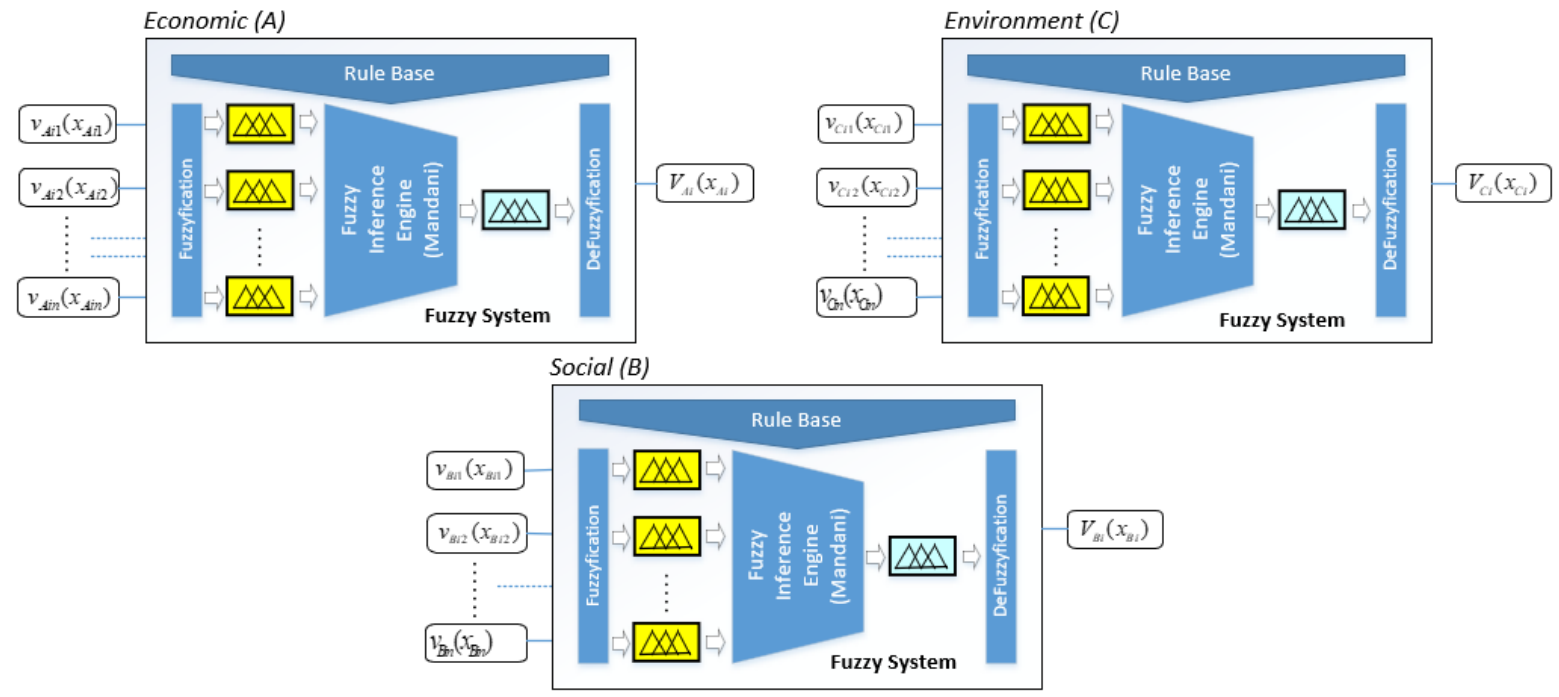

Figure 5. Implementation of each fuzzy system's implementation. 
Table 3. Pertinence functions and linguistic levels, regarding FS's variable inputs $v_{i j}^{g j}\left(x_{i j}^{g j}\right)$.

\begin{tabular}{|c|c|c|}
\hline Fuzzy Set & Membership Function & $\begin{array}{c}\text { Parameters } \\
{[\varphi, \chi, \psi]}\end{array}$ \\
\hline Not Preferable & The candidate does not accomplish at all this sub criterion & $(0,0,0.25)$ \\
\hline Low Preferable & The candidate somehow accomplishes this sub criterion & $(0,0.25,0.50)$ \\
\hline Reasonable Preferable & The candidate reasonably accomplishes this sub criterion & $(0.25,0.50,0.75)$ \\
\hline Preferable & The candidate seems to fulfill this criterion & $(0.5,0.75,1.0)$ \\
\hline Highly Preferable & The candidate fulfills this criterion & $(0.75,1,1)$ \\
\hline
\end{tabular}

Table 4. Pertinence functions and linguistic levels, regarding FS's variable outputs $V_{i}^{g}\left(x_{i}^{g}\right)$.

\begin{tabular}{cccc}
\hline Fuzzy Set & Membership Function & $\begin{array}{c}\text { Parameters } \\
{[\varphi, \chi, \psi]}\end{array}$ & $(0,0,0.25)$ \\
\hline Not Preferable & The candidate does not accomplish at all this criterion & $(0,0.25,0.50)$ \\
\hline Low Preferable & The candidate somehow accomplishes this criterion & $(0.25,0.50,0.75)$ \\
\hline $\begin{array}{c}\text { Reasonable } \\
\text { Preferable }\end{array}$ & The candidate reasonably accomplishes this criterion & $(0.5, \mathbf{0 . 7 5 , 1 . 0 )}$ \\
\hline Preferable & The candidate seems to fulfill this criterion & $(\mathbf{0 . 7 5 , 1 , 1 )}$ \\
\hline Highly Preferable & The candidate fulfills this criterion &
\end{tabular}

The implementation of each FS is presented in Figure 5.

With regards to each FS defined here, triangular membership functions were used (Figure 5) with the correspondent parameters, presented in Tables 1 and 2.

The inference rules were then deployed by using Mamdani's inference mechanism, given its intuitive method, which is highly adequate for the human entries/inputs and widely accepted in the literature as well $[27,69]$.

Through the model's architecture presented in Figure 3 and based on the FS's implementation on MATLAB (Figure 5), each fuzzy system (FS) is regarded as a sustainability dimension (i.e., social (B), environmental (C), or economic (A)), whose set of inference rules can be changed, or even be the same, regarding each one of the three dimensions considered here. Although in this work, we have chosen to maintain the same inference rules, by changing only the inputs and outputs considered for each one of the three dimensions of sustainability.

As is mentioned before, and regarding FS's variable types (input/output), a set of parameters was defined regarding the fuzzy sets, where each one has the corresponding membership function $(\varphi, \chi$, and $\psi)$ (Tables 3 and 4$)$.

With regards to the defuzzification method used here, related to each FS considered in this work, the centroid approach was adopted, given its wide use in other works found in the literature (e.g., [68,69]).

For each one of the FSs considered above, and presented in Figure 5 five membership functions were defined, where each set is correspondent to the FS's inputs and outputs (respectively, Tables 3 and 4). Each membership function was defined as being of the triangular type (Figure 6), and they carry the following (and correspondent) parameters $\varphi$, $\chi$, and $\psi$ (Tables 3 and 4 ).

Given the inference mechanism used here, and based on the output crisp values achieved from each FS considered in this work, we have made use of a set of intervals (Table 5) to convert the corresponding numerical outputs into "linguistic" ones, which are associated with a specific color in order to provide to the board of the managers a graphical result, regarding the score of each candidate (potential partner), on behalf of each criteria considered in this work. 


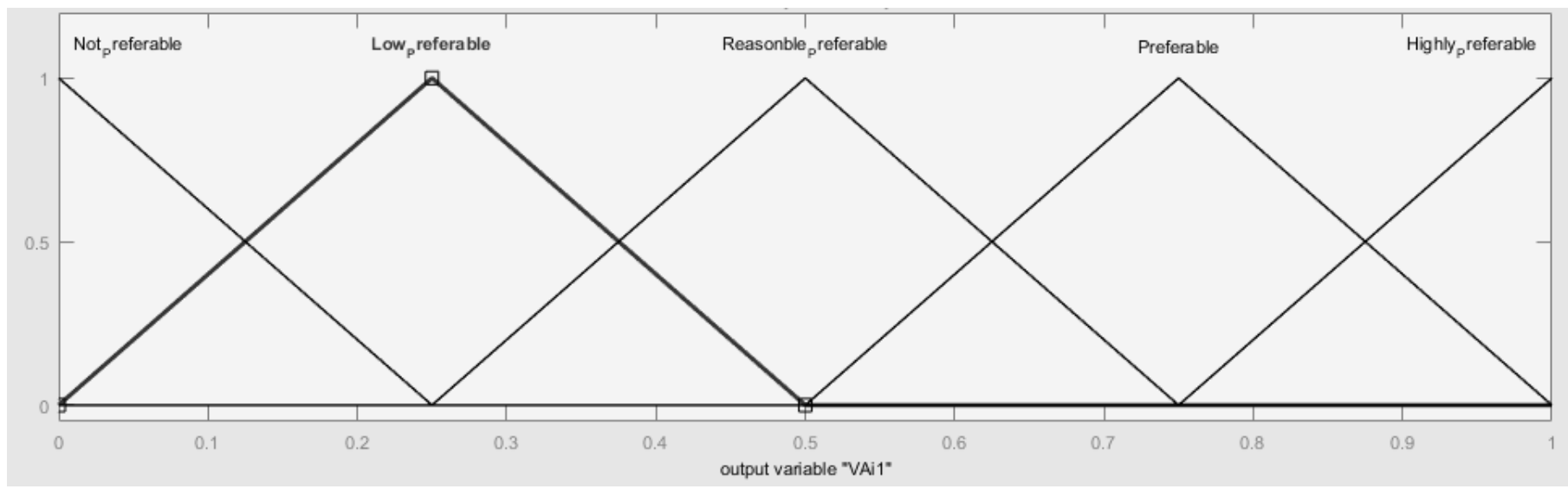

(a)

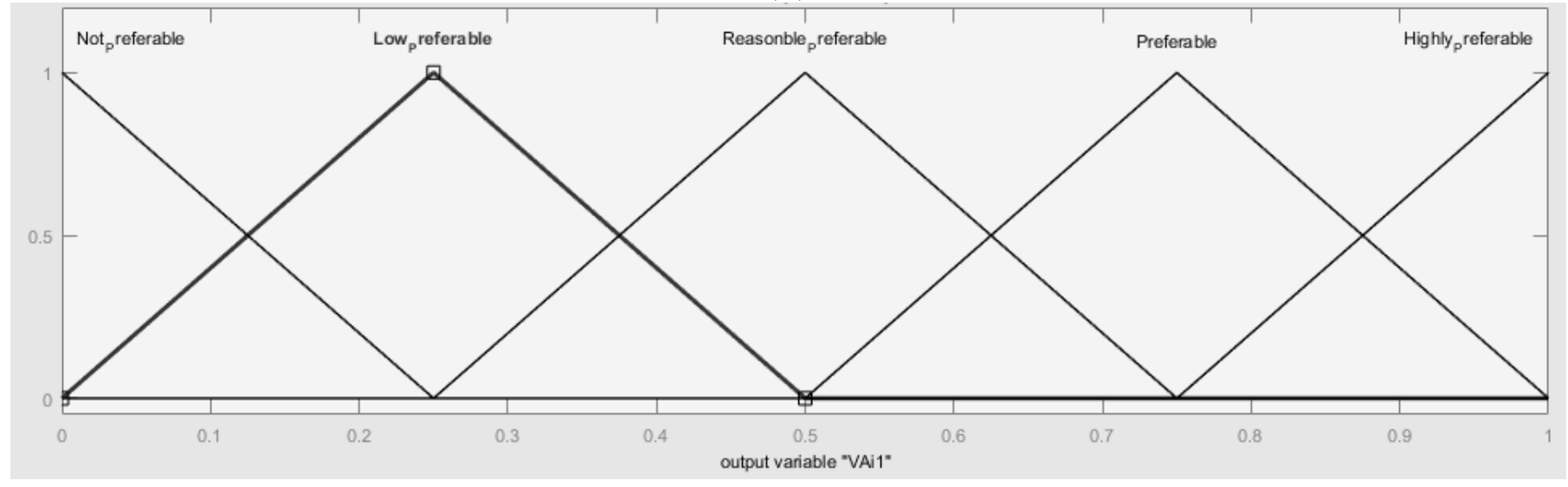

(b)

Figure 6. Membership functions, regarding: (a) inputs $\left(v_{i j}^{g j}\left(x_{i j}^{g j}\right)\right)(\mathbf{b})$ outputs $\left(V_{i}^{g}\left(x_{i}^{g}\right)\right)$.

Table 5. Conversion of linguistic values in numerical format.

\begin{tabular}{cc}
\hline & Score \\
\hline Linguistic Levels & Numerical Correspondence \\
\hline Not Preferable & {$[0,0.2]$} \\
\hline Low Preferable & {$[0.2,0.4]$} \\
\hline Reasonable Preferable & {$[0.4,0.6]$} \\
Preferable & {$[0.6,0.8]$} \\
\hline Highly Preferable & {$[0.8,1.0]$} \\
\hline
\end{tabular}

A similar approach will be used, in order to provide to the board of managers (DM) a graphical result, regarding the overall preference degree level (overall score regarding Partner i), associated with each candidate, based on the numerical outputs obtained.

\section{Case Study, Results, and Discussion}

For the validation of the model proposed here, we have used a case study, based on a $\mathrm{CN}$, established with the purpose to develop an electric vehicle in an OI context, which was used to reach a set of critical innovations required to achieve a sustainable competitive advantage when launching the final product to the market.

This $\mathrm{CN}$ is formed by 14 partners, where some of them are industries from different areas, while others include two R\&D centers and one military institution.

One motivation of this "virtual enterprise", as is mentioned in some of the other works found in the literature (e.g., [18,34]), was to share different core competencies, resources, and skills from (and between) each partner involved, to obtain a set of innovations regarding the product's development. Another motivation had to do with the attractiveness 
degree, needed to raise the credibility of the project, in order to increase the chances of obtaining the necessary funds, either by public funds, from the European Union, or by private funds, related with private investors, such as business angels.

One of the project's final goals is related to vehicle autonomy, which was achieved by performing a set of innovations to increase the car's efficiency, as well as the energy storage capacity.

Other goals include the decrease in the time-to-market and the "pioneer advantage" (given the final shape of the vehicle), needed to achieve (and consolidate) a market niche.

According to another recent study [72], other small innovations have been achieved through the development of the car's components, and by joining different organizations (partners) with different competences (Figure 7). Some of them share common goals, regarding the car components to be developed.

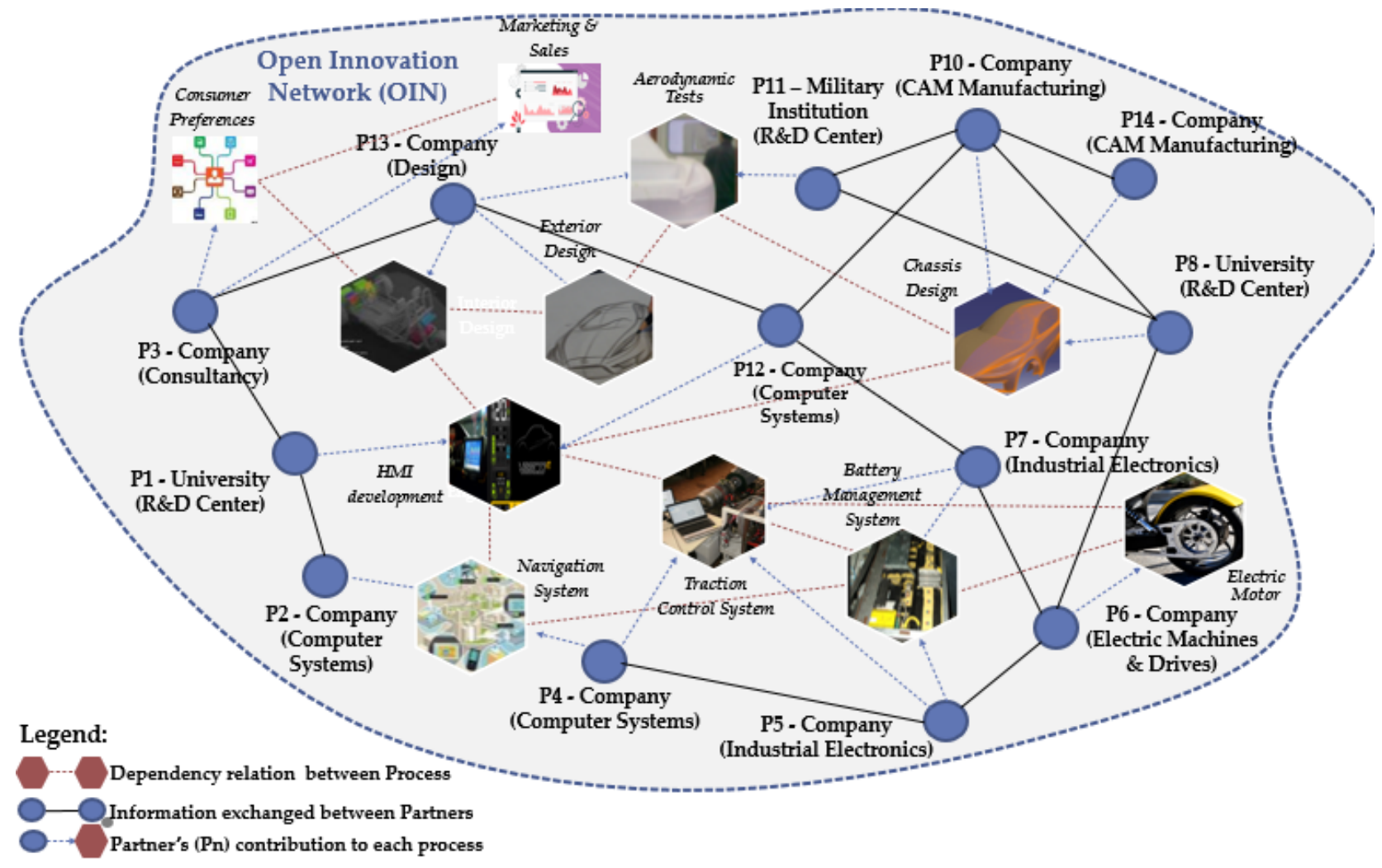

Figure 7. Some of the competencies shared between the different partners and processes involved [76].

Depending on the nature of the process, the organizations involved in this collaborative network (CN) have assumed a different nature (Figure 7). Some of them have involved universities, while others have involved manufacturers, consultancy firms, even including a military institution.

Along with the diversity in terms of nature within the organization, there is diversity within the competencies demanded in each process, given the interdisciplinary nature of new product development (NPD). Therefore, the competencies needed by the $\mathrm{CN}$ were CAM engineering, marketing and sales, computer systems engineering, industrial electronics, design of interiors/exteriors, and aerodynamic tests (fluid mechanics), among others.

Therefore, and given this interdisciplinarity mentioned here, the selection of the CN's right partner must comply with a series of demands, where some of them are related with social and environmental concerns.

Based on Figure 7, and from the work of [72], we can systematize the CN's assets involved (competencies and resources), as well as the partners and the external suppliers 
involved. It is also possible to define each partner's contribution $(\mathrm{Km})$ regarding each process (Prn) involved (KmPrn) (Figure 8).

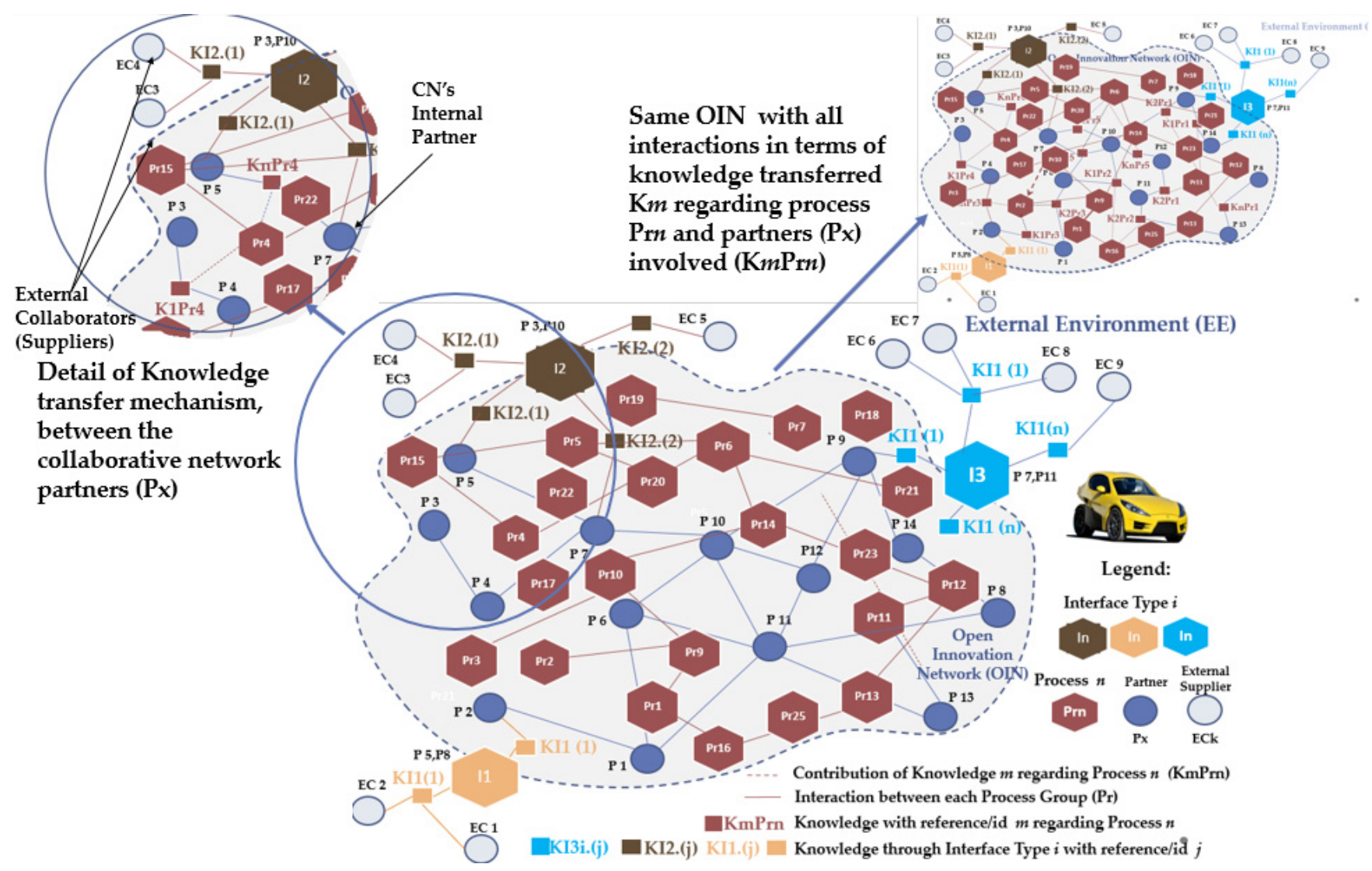

Figure 8. CN's partner and processes involved in the development of the final product (adapted from [76]).

Each network's actor (CN's partner) is involved, at least, in one activity $m$, regarding a process $n(\mathrm{KmPrn})$, where each activity can be described in terms of knowledge, changed between the partners involved (Figure 8). Given the high quantity of processes involved in Figure 8, a part of the network is zoomed in, where we can see the CN's partners (Px) as well as the processes (PRn) and the knowledge related to each activity (Am) exchanged between each Px and regarding the same PRn.

From the entire list of process existed, we have selected some of the processes involved (from a group of 25 in total) as an example, which was used to build this case study (Table 6) and to provide some support to the CN's managers, by selecting two partners.

Thus, in Table 6, we can see the processes used, as well as the partners involved.

From that group, we have defined two more partners for the activities/knowledge mechanisms K4Pr16 and K2Pr11, by following the managers needs at that time.

Based on the table presented above, it is possible to know what partners are needed to fulfill a CN's needs, as well as what process and activity that partner will participate in.

This situation can be better observed in Figure 9, by using the open innovation network (OIN), presented before (Figure 8 ). 
Table 6. Process's description and partners involved (based on [39]).

\begin{tabular}{|c|c|c|c|c|}
\hline Process & Ref. & Activity & Ref. & Partners Involved \\
\hline$\ldots$ & $\ldots$ & $\ldots$ & $\ldots$ & $\ldots$ \\
\hline \multirow{4}{*}{ Marketing } & \multirow{4}{*}{ [5] } & Market studies & K01Pr5 & P8, P7 \\
\hline & & Consumer's requirements & K02Pr5 & P8, P7 \\
\hline & & $\ldots$ & $\ldots$ & $\ldots$ \\
\hline & & Publicity & K4Pr5 & P3 \\
\hline \multirow{2}{*}{ Human machine interface (HMI) } & \multirow{2}{*}{ [8] } & Software development & K01Pr8 & P6, P7 \\
\hline & & PCB development and tests & K02Pr8 & P4, P9 \\
\hline Electronic stability program (ESP) & [9] & System development & K01Pr9 & $\mathrm{P} 2,(?)$ \\
\hline \multirow{3}{*}{ Aerodynamics } & \multirow{3}{*}{ [10] } & Modelling studies & K01Pr10 & P14 \\
\hline & & Prototype development & K02Pr10 & P5 \\
\hline & & Aerodynamic Tests & K03Pr10 & P12 \\
\hline \multirow{3}{*}{ GPS navigation system } & \multirow{3}{*}{ [11] } & Communications module & K01Pr11 & P2, P8 \\
\hline & & Software development & K02Pr11 & $\begin{array}{l}\text { P11, P12, } \\
\text { P15(?) }\end{array}$ \\
\hline & & Tests on site & K03Pr11 & P10 \\
\hline$\ldots$ & $\ldots$ & $\ldots$ & $\ldots$ & $\ldots$ \\
\hline \multirow{5}{*}{ Traction control system } & \multirow{5}{*}{ [16] } & Electronics & K01Pr16 & P9 \\
\hline & & Interface with system's BMS & K02Pr16 & $\mathrm{P} 11, \mathrm{P} 12$ \\
\hline & & Interface with system's ESP & K03Pr16 & P13, P11 \\
\hline & & $\begin{array}{l}\text { Electronics system's interface } \\
\text { with the electric motor }\end{array}$ & K04Pr16 & P6, P10, P11, P16 (?) \\
\hline & & Tests & K05Pr16 & P11 \\
\hline$\ldots$ & $\ldots$ & $\ldots$ & $\ldots$ & $\ldots$ \\
\hline \multirow{2}{*}{ Battery management system (BMS) } & \multirow{2}{*}{ [20] } & System development & K01Pr20 & P2, P10 \\
\hline & & System's tests & K02Pr20 & P10 \\
\hline$\ldots$ & $\ldots$ & $\ldots$ & $\ldots$ & $\ldots$ \\
\hline \multirow{2}{*}{ Power converters } & \multirow{2}{*}{ [25] } & System development & K01Pr25 & P8, P11 \\
\hline & & System's tests & K02Pr25 & P10 \\
\hline
\end{tabular}

Through Table 6 and Figure 9, it is possible to define the location of each (required) partner over the OIN, as well as the processes and activities associated. In this case, the $\mathrm{CN}$ needed an additional partner for the activity "software development", related to the development of the "GPS navigation system" process (K02Pr11). The CN also needed an additional partner for the activity "electronics system's interface with the electric motor", related to the development of the "traction control system" process (K04Pr16).

For each process involved, there is a team leader responsible, on behalf of the CN's board management directives.

Thus, and to accomplish such a goal, each team leader, regarding the process that needs an additional partner, selected (and contacted) a group of potential partners to be further assessed as candidates, in order to build two lists, each one representing a list of potential candidates to fulfill one of the two available places defined before.

Each list of potential candidates is a result of the selection process undertaken in this case study and used to validate the model proposed here. 


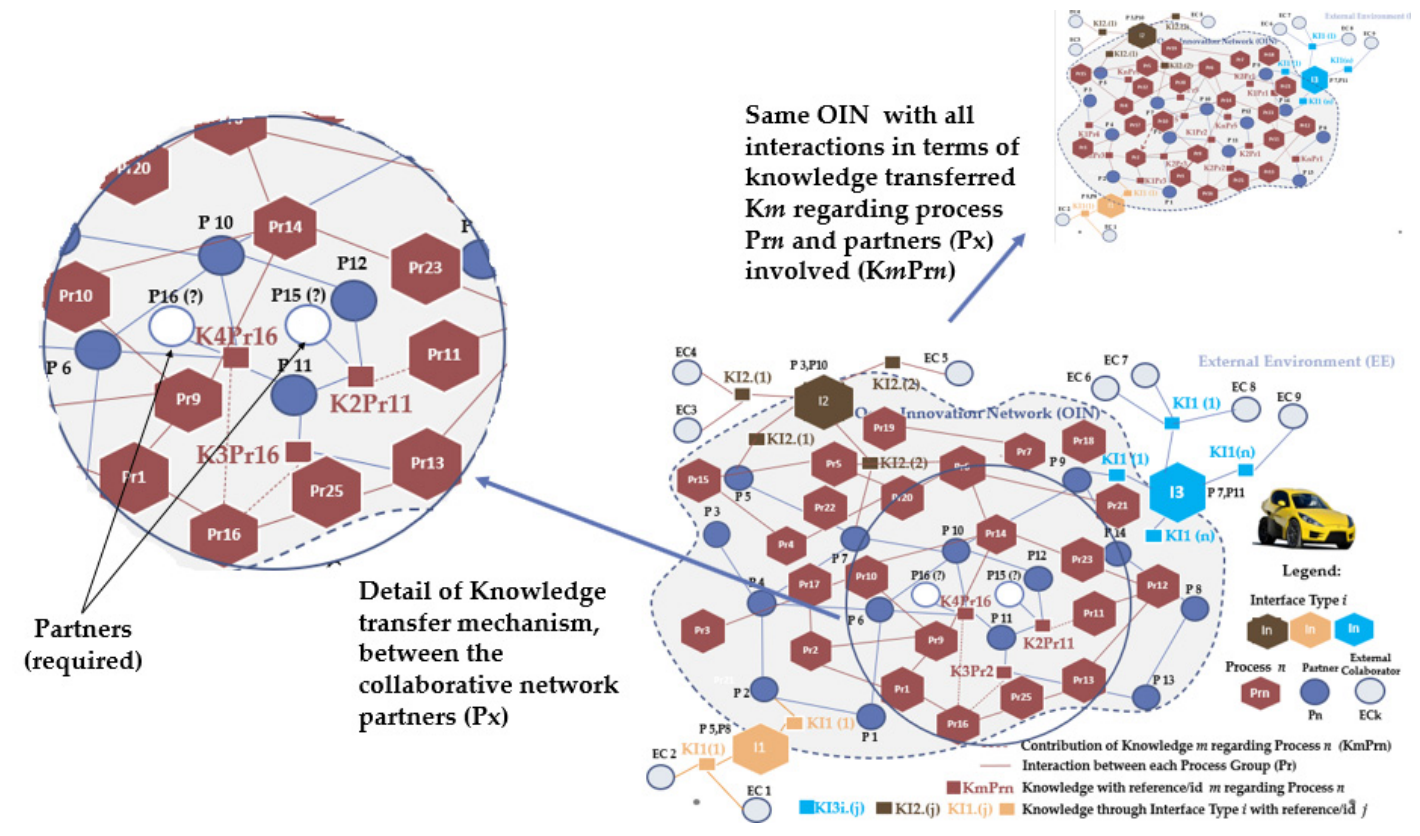

Figure 9. Partners (required) for the processes Pr16 and Pr11 (adapted from [76]).

For that purpose, we have used, at the time as this case study, one of the partner's search processes presented on the literature review (see Section 2.2), supported on the "network-based studies" [53-56], which were based on the individual relationships between the CN's partners and their own cooperation partners (suppliers, I\&D centers, etc.). The lists of candidates, respectively, regarding the two available partners (P15 and P16) are presented below, through the correspondent tables, Tables 7 and 8 .

Table 7. List of candidates to fulfill the place (P15) required for the partnership on behalf of K02Pr11's process.

\begin{tabular}{|c|c|c|c|}
\hline \multirow{2}{*}{ Process Reference } & \multirow{2}{*}{ Partners (Required) } & \multicolumn{2}{|c|}{ Partner (s) Candidate (s) } \\
\hline & & Name & Organization \\
\hline \multirow{9}{*}{ K02Pr11 } & & "A1" & Public-University \\
\hline & & “B1" & Private-Company \\
\hline & & "C1" & Private-University \\
\hline & 3 partners & “D1" & Private-Company \\
\hline & Existing: P11, P12 & "E1" & Public-R\&D Center \\
\hline & Required: P15 & “F1" & Public_-University \\
\hline & & “G1" & Private-Company \\
\hline & & “H1" & Public-University \\
\hline & & “I1" & Public-University \\
\hline
\end{tabular}

Table 8. List of candidates to fulfill the place (P16) required for the partnership on behalf of K04Pr16's process.

\begin{tabular}{cccc}
\hline Process Reference & Partners (Required) & \multicolumn{2}{c}{ Partner (s) Candidate (s) } \\
\cline { 2 - 3 } & & Name & Organization \\
\cline { 2 - 3 } & & "A2" & Private-University \\
& "B2" & Private-Company \\
K04Pr16 & "C2" & Private-Company \\
& Existing: P06, P10 & "D2" & Public-University \\
& Required: P16 & "E2" & Private-R\&D Center \\
& "F2" & Public-R\&D Center \\
& "H2" & Private-Company \\
& & Private-Company \\
\hline
\end{tabular}


For each process, there is a set of factors/issues, which can conditionate not only the number of available partners to be assessed and selected, but also the evaluation process itself. Some factors include the number of available partners regarding a specific process, the operation costs involved with the same process, and the importance of that process on the product's performance, in order to attend to the consumer's needs, among others.

For that reason, the weights, regarding the relative importance, given to each criterion (i.e., A-economic, B-social, and C-environmental) are not the same. Thus, such weights were defined by each team leader, responsible for each process, and the correspondent CN's board of management (three elements), by using the analytical hierarchical process (AHP) method (Figure 10).

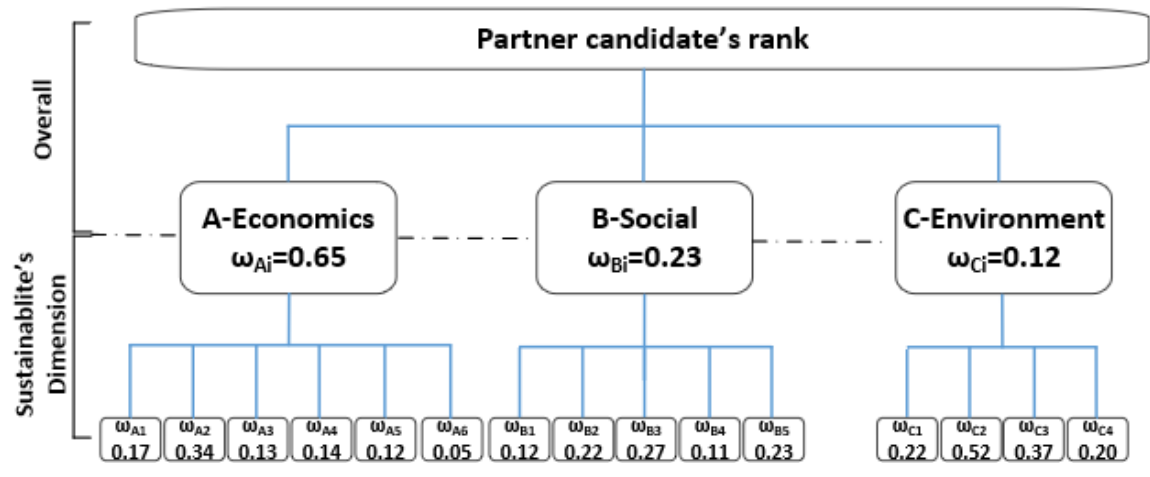

Figure 10. AHP's diagram to obtain a set of weights regarding the processes considered.

After applying multi-attribute value theory (MAVT) to normalize the variable's attributes, the correspondent crisp values are then introduced into the correspondent fuzzy system, related to each sustainability dimension (Figures 4 and 5).

The crisp values $v_{i j}^{g j}\left(x_{i j}^{g j}\right)$ were then converted into fuzzy sets, and by applying a set of rules, based on a set of linguistic values presented in Tables 1 and 2, followed by using the correspondent fuzzy inference mechanism, a set of three outputs $V_{i}^{g}$ was obtained, each one relating to a sustainable development dimension, in order to obtain the partner's score. The input and output values, regarding both processes involved, are presented in Tables 9 and 10, respectively, relating to the K02Pr11 and K04Pr16 process.

Table 9. Model's inputs and outputs regarding K02Pr11's activity (Pr11).

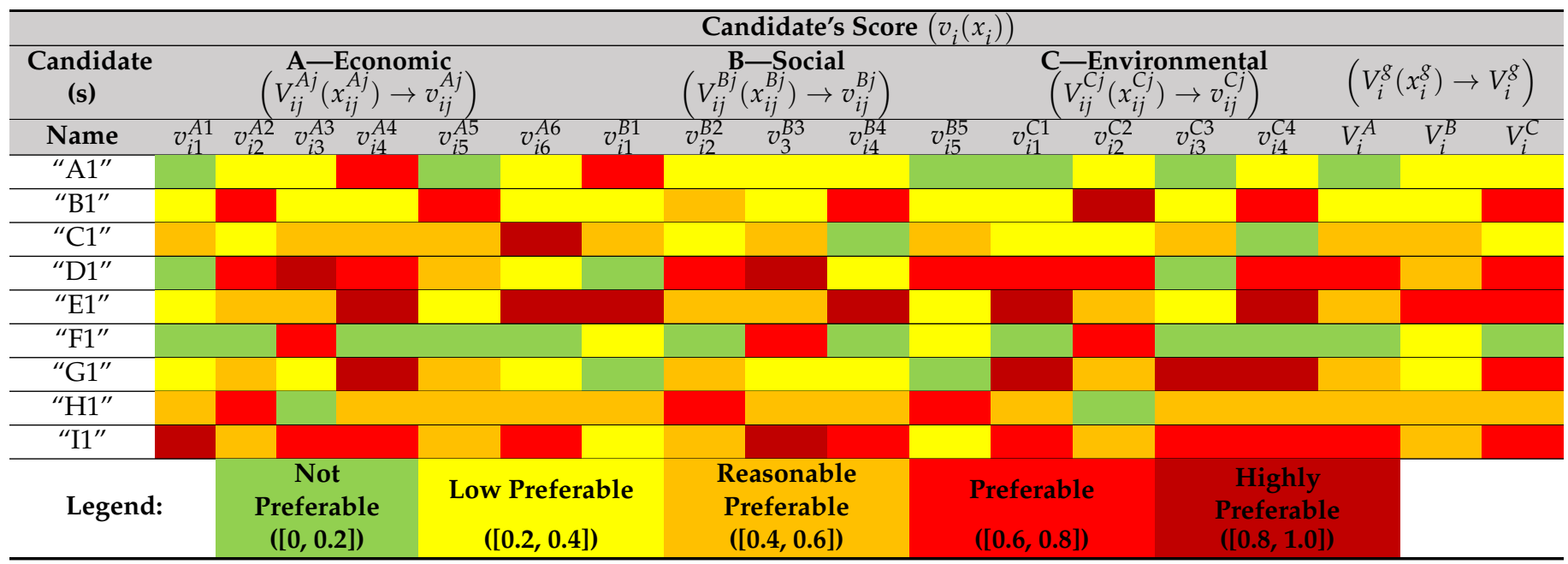


Table 10. Model's inputs and outputs regarding K04Pr16's activity (Pr16).

\begin{tabular}{ccccccccccccc}
\hline \multicolumn{10}{c}{ Partner's Score $\left(v_{i}\left(x_{i}\right)\right)$} & \multicolumn{10}{c}{ C-Environmental } \\
(s)
\end{tabular}

As is referred to before, we have settled a numerical correspondence between the (crisp) values $\left(v_{i j}^{g j}\left(x_{i j}^{g j}\right)\right)$ and the correspondent linguistic levels defined before (Tables 3 and 4 ), by defining a set of intervals, based on the ones presented in Table 5.

Based on the obtained results presented in Tables 9 and 10, namely, through $V_{i}^{A}\left(x_{i}^{A}\right)$, $V_{i}^{B}\left(x_{i}^{B}\right)$, and $V_{i}^{C}\left(x_{i}^{C}\right)$, we have obtained the overall results, presented in Tables 11 and 12. By using the FS outputs $\left(V_{i}^{A}\left(x_{i}^{A}\right), V_{i}^{B}\left(x_{i}^{B}\right) V_{i}^{C}\left(x_{i}^{C}\right)\right)$ and by corresponding them with the linguistic levels, according to Table 5 , we have achieved the overall score of each one of the candidates considered on both processes. The weights $\omega_{A i}, \omega_{B i}$, and $\omega_{C i}$ were previously achieved through the AHP method (Figure 10) and define the relative importance given by the decision makers (DM), regarding each process considered here.

Table 11. Overall results, regarding each partner candidate and K02Pr11's activity (Pr11).

\begin{tabular}{|c|c|c|c|c|c|c|c|c|c|c|c|}
\hline \multicolumn{9}{|c|}{ Partner Candidates (Rank) } & \multicolumn{3}{|c|}{ Partner Candidates (Ordered Rank) } \\
\hline Name & Organization & $V_{i}^{A}\left(x_{j}^{A}\right)$ & $V_{i}^{B}\left(x_{j}^{B}\right)$ & $V_{i}^{\mathrm{C}}\left(x_{j}^{\mathrm{C}}\right)$ & $\omega_{A i}$ & $\omega_{B i}$ & $\omega_{C i}$ & $P S_{n}$ & Name & Organization & $P S_{n}$ \\
\hline “A1" & $\begin{array}{c}\text { Public- } \\
\text { University }\end{array}$ & 0.15 & 0.25 & 0.23 & 0.65 & 0.23 & 0.12 & 0.18 & “D1" & Private-Company & 0.66 \\
\hline “B1" & $\begin{array}{l}\text { Private- } \\
\text { Company }\end{array}$ & 0.39 & 0.22 & 0.67 & 0.65 & 0.23 & 0.12 & 0.38 & “I1" & Public-University & 0.64 \\
\hline "C1" & $\begin{array}{c}\text { Private- } \\
\text { University }\end{array}$ & 0.57 & 0.52 & 0.22 & 0.65 & 0.23 & 0.12 & 0.52 & “E1” & Public-R\&D Center & 0.55 \\
\hline “D1" & $\begin{array}{l}\text { Private- } \\
\text { Company }\end{array}$ & 0.72 & 0.49 & 0.67 & 0.65 & 0.23 & 0.12 & 0.66 & “C1” & Private-University & 0.52 \\
\hline “E1" & $\begin{array}{l}\text { Public-R\&D } \\
\text { Center }\end{array}$ & 0.48 & 0.65 & 0.70 & 0.65 & 0.23 & 0.12 & 0.55 & “G1” & Private-Company & 0.50 \\
\hline "F1" & $\begin{array}{c}\text { Public- } \\
\text { University }\end{array}$ & 0.12 & 0.39 & 0.17 & 0.65 & 0.23 & 0.12 & 0.17 & “H1” & Public-University & 0.45 \\
\hline "G1" & $\begin{array}{l}\text { Private- } \\
\text { Company }\end{array}$ & 0.57 & 0.23 & 0.62 & 0.65 & 0.23 & 0.12 & 0.50 & “B1” & Private-Company & 0.38 \\
\hline “H1" & $\begin{array}{l}\text { Public- } \\
\text { University }\end{array}$ & 0.42 & 0.49 & 0.57 & 0.65 & 0.23 & 0.12 & 0.45 & "A1" & Public-University & 0.18 \\
\hline “I1" & $\begin{array}{c}\text { Public- } \\
\text { University }\end{array}$ & 0.68 & 0.50 & 0.69 & 0.65 & 0.23 & 0.12 & 0.64 & “F1" & Public-University & 0.17 \\
\hline & & & & & & ence $c$ & & & $15 t$ & $3 r d$ & 5 th \\
\hline
\end{tabular}


Table 12. Overall results, regarding each partner candidate and K04Pr16's activity (Pr16).

\begin{tabular}{|c|c|c|c|c|c|c|c|c|c|c|c|}
\hline \multicolumn{9}{|c|}{ Partner Candidates (Rank) } & \multicolumn{3}{|c|}{$\begin{array}{c}\text { Partner Candidates (Ordered } \\
\text { Rank) }\end{array}$} \\
\hline Name & Organization & $V_{i}^{A}\left(x_{j}^{A}\right)$ & $V_{i}^{B}\left(x_{j}^{B}\right)$ & $V_{i}^{\mathrm{C}}\left(x_{j}^{\mathrm{C}}\right)$ & $\omega_{A i}$ & $\omega_{B i}$ & $\omega_{C i}$ & $P S_{n}$ & Nan & Organization & $P S_{n}$ \\
\hline "A2" & Private-University & 0.71 & 0.41 & 0.22 & 0.65 & 0.23 & 0.12 & 0.58 & "D2" & Pubic-University & 0.79 \\
\hline "B2" & Private-Company & 0.52 & 0.24 & 0.35 & 0.65 & 0.23 & 0.12 & 0.44 & "A2" & Private-University & 0.58 \\
\hline “C2” & Private-Company & 0.58 & 0.33 & 0.51 & 0.65 & 0.23 & 0.12 & 0.51 & “E2 & $\begin{array}{l}\text { Private-R\&D } \\
\text { Center }\end{array}$ & 0.59 \\
\hline "D2" & Pubic-University & 0.90 & 0.71 & 0.32 & 0.65 & 0.23 & 0.12 & 0.79 & "C2" & Private-Company & 0.51 \\
\hline “E2" & Private-R\&D Center & 0.58 & 0.61 & 0.59 & 0.65 & 0.23 & 0.12 & 0.59 & "H2" & Private-Company & 0.48 \\
\hline "F2" & Public-R\&D Center & 0.18 & 0.49 & 0.37 & 0.65 & 0.23 & 0.12 & 0.27 & "B2" & Private-Company & 0.44 \\
\hline "G2" & Private-Company & 0.45 & 0.27 & 0.23 & 0.65 & 0.23 & 0.12 & 0.38 & "G2" & Private-Company & 0.38 \\
\hline “H2” & Private-Company & 0.52 & 0.42 & 0.37 & 0.65 & 0.23 & 0.12 & 0.48 & "F2" & $\begin{array}{l}\text { Public-R\&D } \\
\text { Center }\end{array}$ & 0.27 \\
\hline \multicolumn{9}{|c|}{ Preference degree: } & $1 s t$ & $3 r d$ & 5 th \\
\hline
\end{tabular}

In both tables, we have re-ordered the candidates based on their overall score, in order to define the DM's preference order. Thus, and with regards to K02Pr11's activity (Table 9), the best candidate that suits the Pr11's objectives, and especially K02Pr11's activity, is the candidate "D1" (private company). However, the overall score of the second best positioned (candidate "I1") is quite similar to "D1", and it has a better score regarding the social and environmental dimensions. This could be a situation to be reconsidered if the $\mathrm{CN}$ gives high importance to the social and, most of all, more importance to the environmental issues, given its environmental concerns, as well as the normative demands regarding these issues.

These results allow us to perceive that the decision maker can test different scenarios, based on the relative importance given by the CN's board of management to each one of the sustainable dimensions considered here and seeing the marginal benefit of raising the importance in one dimension over another, considering the same partner candidate.

Given the similarity within the overall results, between the first and second candidates, we can also have the situation of the CN's DM, preferring to select a university instead of a company, given other goals that they might have in mind.

With regards to the K04Pr16's activity (Table 10), the best candidate that suits the Pr16's objectives, and especially K04Pr16's activity, is the candidate "D2" (public university). In this case, the first candidate has the total predominance over the second one in all sustainability dimensions. Given the Pr16's DM intentions of including just one partner in this activity, there is no doubt regarding this situation. Although, the analyses could be more difficult, when, instead of pretending to include one candidate, the DM's need to include two candidates. In this sense, we could analyze the partner's score on behalf of the three dimensions considered here.

On both situations, we could also select the partner candidate with the best score regarding a specific sustainability dimension. This issue can be somehow useful when the DM needs to prioritize the partner candidates, based on a specific sustainability dimension.

It can also be possible to consider the second best positioned candidate as the partner required by the $\mathrm{CN}$ for that activity in particular, which allows them to solve a contingency that might occur (e.g., candidate D2 has quit after several meetings, and further negotiations took place), allowing, therefore, the selection of the second best positioned candidate to fulfill the place (in the case of $\mathrm{K} 04 \mathrm{Pr} 16$, it would be the private university, i.e., candidate "A2").

\section{Conclusions}

In this work, we have presented an approach, which was developed to support a group of decision makers when assessing and selecting the most suitable organization to include in their collaborative network $(\mathrm{CN})$ as a partner, affected to a given activity, related to a given process. 
The approach developed here allows them to assess and select a suitable partner, on behalf of the three known sustainability dimensions considered here, namely, economic (A), social (B), and environmental (C).

The approach presented in this work was developed to assess a set of candidates (potential partners) and prioritize them, by using fuzzy logic, in order to deal with human subjectivity when assessing each candidate, based on the $\mathrm{CN}^{\prime}$ 's preferences.

Besides assessing and prioritizing each candidate, based on their attributes, the approach developed here also allows them to perceive which sustainability dimension the partner candidate is more suitable for, based on the CN's objectives.

Additionally, it is also possible with this method to prevent eventual contingencies, regarding one or even more candidates, given a situation that might occur (e.g., unavailability of a suitable candidate), by selecting other partners to fulfill the places left behind by the first ones.

By being a fuzzy-logic-based method, we can also reduce the subjectivity effect related to the decisions, performed in a group context. This issue is revealed to be particularly important when the CN's DM is formed by a group with more than one individual.

However, there were some limitations found in this work, which allow us to point to some future work to be considered here.

One limitation has to do with the relative importance given to each sub criteria, since each sub criteria does not have the same impact over each sustainability dimension.

The integration of risk assessment methods, based on each candidate's history, also allows for better assessment of the candidates, since a better positioned candidate can reveal a high risk in one (or even more) sustainability dimensions in the future.

Author Contributions: Conceptualization, J.S.; Data curation, H.V.G.N.; Formal analysis, R.S.S. and J.M.M.; Funding acquisition, J.M.M.; Investigation, R.S.S. and P.C.M.; Methodology, R.S.S.; Project administration, J.S. and P.C.M.; Resources, J.S.; Software, R.S.S.; Supervision, J.S.; Validation, H.V.G.N.; Visualization, H.V.G.N.; Writing—original draft, P.C.M. and J.M.M.; Writing—review \& editing, H.V.G.N. and J.M.M. All authors have read and agreed to the published version of the manuscript.

Funding: This research received no external funding.

Institutional Review Board Statement: Not applicable.

Informed Consent Statement: Not applicable.

Data Availability Statement: Not applicable.

Conflicts of Interest: The authors declare no conflict of interest.

\section{References}

1. Prahalad, C.K.; Hamel, G. The core competence of the corporation. Harvard Bus. Rev. 2010, 68, 275-292.

2. Wang, L.; Wang, X.; Philipsen, N.J. Network structure of scientific collaborations between China and the EU member states. Scientometrics 2017, 113, 765-781. [CrossRef] [PubMed]

3. Weitzman, M.L. Recombinant growth. Q. J. Econ. 1998, 113, 331-360. [CrossRef]

4. Amabile, T.M. Social psychology of creativity: A consensual assessment technique. J. Pers. Soc. Psychol. 1982, 43, 997-1013. [CrossRef]

5. Amabile, T.M.; Conti, R.; Coon, H.; Lazenby, J.; Herron, M. Assessing the work environment for creativity. Acad. Manag. J. 1996, $39,1154-1184$

6. Hsu, M.L.A.; Chen, F.H. The cross-level mediating effect of psychological capital on the organizational innovation climateemployee innovative behavior relationship. J. Creat. Behav. 2017, 51, 128-139. [CrossRef]

7. Perry-Smith, J.E. Social yet creative: The role of social relationships in facilitating individual creativity. Acad. Manag. J. 2006, 49, 85-101. [CrossRef]

8. Gonzalez-Brambila, C.N.; Veloso, F.; Krackhardt, D. The impact of network embeddedness on research output. Res. Policy 2013, 42, 1555-1567. [CrossRef]

9. Liao, C.H. How to improve research quality? Examining the impacts of collaboration intensity and member diversity in collaboration networks. Scientometrics 2011, 86, 747-761. [CrossRef]

10. Andersen, K.V. The problem of embeddedness revisited: Collaboration and market types. Res. Policy 2013, 42, 139-148. [CrossRef] 
11. Zhou, T.; Lü, L.; Zhang, Y.-C. Predicting missing links via local information. Eur. Phys. J. B 2009, 71, 623-630. [CrossRef]

12. Lotf, J.J.; Azgomi, M.A.; Dishabi, M.R.E. An improved influence maximization method for social networks based on genetic algorithm. Phys. A Stat. Mech. Appl. 2022, 586, 126480. [CrossRef]

13. Wi, H.; Oh, S.; Mun, J.; Jung, M. A team formation model based on knowledge and collaboration. Expert Syst. Appl. 2009, 36, 9121-9134. [CrossRef]

14. Bozzon, A.; Brambilla, M.; Ceri, S.; Silvestri, M.; Vesci, G. Choosing the right crowd: Expert finding in social networks. In Proceedings of the ACM International Conference on Extending Database Technology, Genoa, Italy, 18-22 March 2013; pp. 637-648.

15. Santos, R.; Abreu, A.; Soares, J.; Mendes, F.M.A.S.; Calado, J.M. A Soft Computing Framework to Support Consumers in Obtaining Sustainable Appliances from the Market. Appl. Sci. 2020, 10, 3206. [CrossRef]

16. Abreu, A.; Martins, J.D.M.; Calado, J.M.F. Fuzzy Logic Model to Support Risk Assessment in Innovation Ecosystems. In Proceedings of the 2018 13th APCA International Conference on Control and Soft Computing (CONTROLO), Ponta Delgada, Portugal, 4-6 June 2018; pp. 104-109.

17. Ávila, P.; Mota, A.; Pires, A.; Bastos, J.; Putnik, G.; Teixeira, J. Supplier's selection model based on an empirical study. Procedia Technol. 2012, 5, 625-634. [CrossRef]

18. Tsai, K.-H. Collaborative networks and product innovation performance: Toward a contingency perspective. Res. Policy 2009, 38, 765-778. [CrossRef]

19. Emden, Z.; Calantone, R.J.; Droge, C. Collaborating for new product development: Selecting the partner with maximum potential to create value. J. Prod. Innov. Manag. 2020, 23, 330-341. [CrossRef]

20. Zolghadri, M.; Eckert, C.; Zouggar, S.; Girard, P. Power-based supplier selection in product development projects. Comput. Ind. 2011, 62, 487-500. [CrossRef]

21. Rajesh, R.; Ravi, V. Supplier selection in resilient supply chains: A grey relational analysis approach. J. Clean. Prod. 2015, 86, 343-359. [CrossRef]

22. Kraljic, P. Purchasing must become supply management. Harv. Bus. Rev. 1983, 61, 109-117.

23. Junior, F.R.L.; Osiro, L.; Carpinetti, L.C.R. A comparison between fuzzy AHP and Fuzzy TOPSIS methods to supplier selection. Appl. Soft Comput. 2014, 21, 194-209. [CrossRef]

24. Kaya, T.; Kahraman, C. Multicriteria decision making in energy planning using a modified fuzzy TOPSIS methodology. Expert Syst. Appl. 2011, 38, 6577-6585. [CrossRef]

25. Abdullah, L.; Najib, L. Sustainable energy planning decision using the intuitionistic fuzzy analytic hierarchy process: Choosing energy technology in Malaysia. Int. J. Sustain. Energy 2014, 35, 360-377. [CrossRef]

26. Kannan, D.; Khodaverdi, R.; Olfat, L.; Jafarian, A.; Diabat, A. Integrated fuzzy multi criteria decision making method and multiobjective programming approach for supplier selection and order allocation in a green supply chain. J. Clean. Prod. 2013, 47, 355-367. [CrossRef]

27. Yue, Z. TOPSIS-based group decision-making methodology in intuitionistic fuzzy setting. Inf. Sci. 2014, 277, 141-153. [CrossRef]

28. Büyüközkan, G.; Çifçi, G.; Güleryüz, S. Strategic analysis of healthcare service quality using fuzzy AHP methodology. Expert Syst. Appl. 2011, 38, 9407-9424. [CrossRef]

29. Xu, Z.; Liao, H. Intuitionistic Fuzzy Analytic Hierarchy Process. IEEE Trans. Fuzzy Syst. 2014, 22, 749-761. [CrossRef]

30. Chesbrough, H. The future of open innovation. Res. Manag. 2017, 60, 35-38. [CrossRef]

31. Du, J.; Leten, B.; Vanhaverbeke, W. Managing open innovation projects with science-based and market-based partners. Res. Policy 2014, 43, 828-840. [CrossRef]

32. Albats, E.; Alexander, A.; Mahdad, M.; Miller, K.; Post, G. Stakeholder management in SME open innovation: Interdependences and strategic actions. J. Bus. Res. 2020, 119, 291-301. [CrossRef]

33. Chistov, V.; Aramburu, N.; Carrillo-Hermosilla, J. Open eco-innovation: A bibliometric review of emerging research. J. Clean. Prod. 2021, 311, 127627. [CrossRef]

34. Fetterhoff, T.J.; Voelkel, D. Managing Open Innovation in Biotechnology. Res. Manag. 2006, 49, 14-18. [CrossRef]

35. Huizingh, E.K. Open innovation: State of the art and future perspectives. Technovation 2011, 31, 2-9. [CrossRef]

36. Kirschbaum, R. Open innovation in practice. Res.-Technol. Manag. 2015, 48, 24-28. [CrossRef]

37. Slowinski, G.; Sagal, M.W. Good Practices in Open Innovation. Res. Manag. 2010, 53, 38-45. [CrossRef]

38. Bilgram, V.; Füller, J.; Bartl, M.; Biel, S.; Miertsch, H. Eine Allianz gegen Flecken. Harv. Bus. Manag. 2013, 35, 62-68.

39. Gassmann, O. Crowdsourcing-Innovations Management Mit Schwarmintelligenz: Interaktiv Ideen Finden; Kollektives Wissen Effektiv Nutzen; Mit Fallbeispielen und Checklisten, 2. Aufl; Carl Hanser: München, Germany, 2013.

40. Echterhoff, N. Systematik zur Planung Von Cross-Industry-Innovationen. Ph.D. Dissertation, Verlagshaus Monsenstein und Vannerdat OHG, München, Germany, 2014.

41. Van Beers, C.; Zand, F. R\&D cooperation, partner diversity, and innovation performance. An empirical analysis. J. Prod. Innov. Manag. 2014, 31, 292-312.

42. West, J.; Bogers, M. Leveraging External Sources of Innovation: A Review of Research on Open Innovation. J. Prod. Innov. Manag. 2014, 31, 814-831. [CrossRef]

43. Giannopoulou, E.; Yström, A.; Ollila, S. Turning open innovation into practice: Open innovation research through the lens of managers. Int. J. Innov. Manag. 2011, 15, 505-524. [CrossRef] 
44. Lazzarotti, V.; Visconti, F.; Pellegrini, L.; Gjergji, R. Are there any differences between family and non-family firms in the open innovation era? Lessons from the practice of European manufacturing companies. Int. J. Technol. Intell. Plan. 2017, 11, 279. [CrossRef]

45. Laursen, K.; Salter, A. The paradox of openness: Appropriability, external search and collaboration. Res. Policy 2014, 43, 867-878. [CrossRef]

46. Bengtsson, L.; Lakemond, N.; Lazzarotti, V.; Manzini, R.; Pellegrini, L.; Tell, F. Open to a select few? Matching partners and knowledge content for open innovation performance. Creat. Innov. Manag. 2014, 24, 72-86. [CrossRef]

47. Markovic, S.; Bagherzadeh, M. How does breadth of external stakeholder co-creation influence innovation performance? Analyzing the mediating roles of knowledge sharing and product innovation. J. Bus. Res. 2018, 88, 173-186. [CrossRef]

48. Solesvik, M.Z.; Gulbrandsen, M. Partner selection for Open Innovation. Technol. Innov. Manag. Rev. 2013, 3, 11-16. [CrossRef]

49. Lopez-Vega, H.; Tell, F.; Vanhaverbeke, W. Where and how to search? Search paths in open innovation. Res. Policy 2016, 45, 125-136. [CrossRef]

50. Vanhaverbeke, W. Managing Open Innovation in SMEs; Cambridge University Press: Cambridge, UK, 2017.

51. Aloini, D.; Dulmin, R.; Farina, G.; Mininno, V.; Pellegrini, L. Structured selection of partners in open innovation: An IF-TOPSIS based approach. Meas. Bus. Excell. 2016, 20, 53-66. [CrossRef]

52. Guertler, M.R.; Lindemann, U. Identifying Open Innovation partners: A methodology for strategic partner selection. Int. J. Innov. Manag. 2016, 20, 1640011. [CrossRef]

53. Von Hippel, E.; Franke, N.; Prügl, R. Efficient Identification of Leading-Edge Expertise. Screening vs. Pyramiding. In Proceedings of the PICMET Conference: Technology Management for the Global Future, Istanbul, Turkey, 8-13 July 2016 ; pp. 884-897.

54. Newmeyer, C.; Venkatesh, R.; Chatterjee, R. Cobranding arrangements and partner selection: A conceptual frame-work and managerial guidelines. J. Acad. Mark. Sci. 2014, 42, 103-118. [CrossRef]

55. Belz, F.-M.; Baumbach, W. Netnography as a method of lead user identification. Creat. Innov. Manag. 2010, 19, 304-313. [CrossRef]

56. Yoon, B.; Song, B. A systematic approach of partner selection for open innovation. Ind. Manag. Data Syst. 2014, 114, 1068-1093. [CrossRef]

57. Tojeiro-Rivero, D.; Moreno, R. Technological cooperation, R\&D outsourcing, and innovation performance at the firm level: The role of the regional context. Res. Policy 2019, 48, 1798-1808. [CrossRef]

58. Hossain, M. A review of literature on open innovation in small and medium-sized enterprises. J. Glob. Entrep. Res. 2015, 5, 6. [CrossRef]

59. Poetz, M.K.; Prügl, R. Crossing domain-specific boundaries in search of innovation. Exploring the potential of pyramiding. J. Prod. Innov. Manag. 2010, 27, 897-914. [CrossRef]

60. Su, W.; Huang, S.X.; Fan, Y.S.; Mak, K.L. Integrated partner selection and production-distribution planning for manufacturing chains. Intell. Enterp. Syst. 2015, 84, 32-42. [CrossRef]

61. Meige, A.; Golden, B. Multistep dynamic expert sourcing: A novel approach for open Innovation platforms. In A Guide to Open Innovation and Crowdsourcing: Practical Tips Advice and Examples from Leading Experts in the Field; Sloane, P., Ed.; Kogan Page: London, UK; Philadelphia, PA, USA, 2011; Volume 23, pp. 189-196.

62. Chen, Y. A study on the modes of open innovation matched with firms' internal capabilities. In Proceedings of the International Conference on Management of Engineering \& Technology (PICMET), Kanazawa, Japan, 27-31 July 2014.

63. Zhang, G.; Wang, X.; Duan, H.; Zheng, L.J. How do new entrants' pre-entry technological backgrounds impact their cross-industry innovation performances? A retrospective study of the mobile phone vendors. Technovation 2021, 100, 102176. [CrossRef]

64. Jeppesen, L.B.; Lakhani, K.R. Marginality and Problem-Solving Effectiveness in Broadcast Search. Organ. Sci. 2010, 21, 1016-1033. [CrossRef]

65. Hernandez-Vivanco, A.; Cruz-Cázares, C.; Bernardo, M. Openness and management systems integration: Pursuing innovation benefits. J. Eng. Technol. Manag. 2018, 49, 76-90. [CrossRef]

66. Gassmann, O.; Daiber, M.; Enkel, E. The role of intermediaries in cross-industry innovation processes. RED Manag. 2011, 41, 457-469. [CrossRef]

67. Lin, L.; Yuan, X.-H.; Xia, Z.-Q. Multicriteria fuzzy decision-making methods based on intuitionistic fuzzy sets. J. Comput. Syst. Sci. 2007, 73, 84-88. [CrossRef]

68. Boran, F.E.; Boran, K.; Menlik, T. The evaluation of renewable energy technologies for electricity generation in Turkey using intuitionistic fuzzy TOPSIS. Energy Sources Part B Econ. Plan. Policy 2012, 7, 81-90. [CrossRef]

69. Joshi, D.; Kumar, S. Intuitionistic fuzzy entropy and distance measure based TOPSIS method for multi-criteria decision making. Egypt. Inform. J. 2014, 15, 97-104. [CrossRef]

70. Dias, A.S.M.E.; Abreu, A.; Navas, H.V.G.; Santos, R. Proposal of a Holistic Framework to Support Sustainability of New Product Innovation Processes. Sustainability 2020, 12, 3450. [CrossRef]

71. Santos, R.; Abreu, A.; Dias, A.; Calado, J.; Anes, V.; Soares, J. A Framework for Risk Assessment in Collaborative Networks to Promote Sustainable Systems in Innovation Ecosystems. Sustainability 2020, 12, 6218. [CrossRef]

72. Guertler, M.R.; Sick, N. Exploring the enabling effects of project management for SMEs in adopting open innovationA framework for partner search and selection in open innovation projects. Int. J. Proj. Manag. 2021, 39, 102-114. [CrossRef]

73. Uren, V.; Miller, T.; Da Campo, R.; Dadzie, A.-S. A model for partner selection criteria in energy from waste projects. J. Clean. Prod. 2021, 279, 123582. [CrossRef] 
74. Li, E.Y.; Liao, C.H.; Yen, H.R. Co-authorship networks and research impact: A social capital perspective. Res. Policy 2013, 42, 1515-1530. [CrossRef]

75. Abreu, A.; Santos, R.; Calado, J.; Requeijo, J. A Fuzzy Logic Model to Enhance Quality Management on R\&D Units. KnE Eng. 2020, 5, 285-298. [CrossRef]

76. Santos, R.; Abreu, A.; Anes, V. Developing a Green Product-Based in an Open Innovation Environment. Case Study: Electrical Vehicle. In Collaborative Networks and Digital Transformation; Camarinha-Matos, L., Afsarmanesh, H., Antonelli, D., Eds.; IFIP Advances in Information and Communication Technology; Springer: Cham, Switzerland, 2019; Volume 568. 